$\mathbb{P}$ periodica polytechnica

Civil Engineering

58/4 (2014) 397, 422

doi: $10.3311 /$ PPci.7466

http://periodicapolytechnica.org/ci

Creative Commons Attribution (1)

RESEARCH ARTICLE

\section{Chaotic biogeography algorithm for size and shape optimization of truss structures with frequency constraints}

\author{
Shahin Jalili / Yousef Hosseinzadeh / Ali Kaveh
}

Received 2014-04-04, revised 2014-10-08, accepted 2014-10-09

\begin{abstract}
Size and shape optimization of truss structures with natural frequency constraints is inherently nonlinear dynamic optimization problem with several local optima. Therefore the optimization method should be sagacious enough to avoid being trapped in local optima and in this way to reduce premature convergence. To address this problem, we develop a Chaotic Biogeography-Based Optimization (CBBO) algorithm which combines the chaos theory and the biogeography-based optimization (BBO) to achieve an efficient optimization method. In this method, new chaotic migration and mutation operators are proposed to enhance the exploration ability of $B B O$. The performance of the method is demonstrated through five benchmark design examples with size and shape variables associated by multiply frequency constraints. The results show the efficiency and robustness of proposed method and in most cases, CBBO finds a relatively lighter structural weight than those previously reported results in the literature.
\end{abstract}

\section{Keywords}

Biogeography-based optimization $\cdot$ Chaos $\cdot$ Size and shape optimization · Truss structures

\section{Shahin Jalili}

Department of Civil Engineering, University of Tabriz, Building No. 7, 5166416471, Tabriz, Iran

e-mail: 1shahin191@ms.tabrizu.ac.ir

\section{Yousef Hosseinzadeh}

Department of Civil Engineering, University of Tabriz, Building No. 7, 5166416471, Tabriz, Iran

e-mail: hosseinzadeh@tabrizu.ac.ir

\section{Ali Kaveh}

Center of Excellence for Fundamental Studies in Structural Engineering, University of Science and Technology, Narmak, Tehran-16, Iran

e-mail: alikaveh@iust.ac.ir

\section{Introduction}

With increasing the desire to minimize constructional costs of the structures and reducing the amount of material usage, optimal design of structures is gaining much attention. This paper addresses the optimal design of truss structures with natural frequency constraints, which has important applications in the dynamic response analyses.

In fact, in most of the low frequency vibration problems, the response of the structure to dynamic excitation is primarily a function of its fundamental frequency and mode shapes [1]. In some cases, a certain excitation frequency may cause resonance phenomenon. In such cases, the ability to manipulate the selected frequency can significantly improve the performance of the structure. Thus, the control of natural frequencies of the structure plays an important role to keep the structural behavior desirable.

Structural optimization with multiply frequency constraints is a highly nonlinear problem with respect to the design variables associated by non-convex solution space and multiple local minima which makes finding the global optimum a challenging problem. The main objective of this optimization is to minimize the weight of a structure, while satisfying the natural frequency constraints.

Over the past decades, many optimization algorithms have been developed for structural optimization problems with frequency constraints. The early works on the topics mostly use various classical techniques, such as Mathematical Programming (MP) and Optimality criteria (OC) methods, to size optimization of truss structures with frequency constraints. For example, Grandhi and Venkaya [2] used an optimality criterion method based on uniform Lagrangian density for resizing and a scaling procedure to locate the constraint boundary. Sedaghati et al. [3] employed the integrated force method to sizing both truss and beam structures under single and multiply frequency constraints.

On the other hand, the structure response is much more sensitive with respect to joint positions variation, and more effective designs can be generated by optimizing both shape and size parameters [4]. However, the complexity of the optimization 
problem is increases by simultaneous consideration of size and shape variables. This complexity arises from different physical representation of these variables and, sometimes their changes are of widely different orders of magnitude. During the last two decades a number of researches have utilized classical optimization techniques. For instance, Wang et al. [5] proposed an optimality criteria algorithm for combined sizing-layout optimization of three-dimensional truss structure. In this method, the sensitivity analysis helps to determine the search direction and the optimal solution is achieved gradually from an infeasible starting point with a minimum weight increment, and the structural weight is indirectly minimized.

Generally, the above-mentioned classical optimization techniques have several drawbacks, such as computational complexity, dependence on good starting point and premature convergence. As an alternative to the classical optimization approaches, meta-heuristic optimization techniques have been widely utilized and improved to solve engineering optimization problems characterized by non-convex, dis-continuous and non-differentiable. Meta-heuristic algorithms, such as Genetic Algorithm [6], Particle Swarm Optimizer [7], Charged System Search [8] and Big Bang-Big Crunch [9] algorithm are developed by the simulation of the natural processes trying to solve complex optimization problems in a stochastic manner, where other optimization methods have failed to be effective.

Genetic Algorithm (GA) developed by Goldberg [6], inspired from human evolution principles, such as inheritance, mutation, selection, and crossover. Lingyun et al. [10] introduced hybrid Niche Hybrid Genetic Algorithm (NHGA) to shape and size optimization of truss structures with frequency constraints. In this method, the exploitation capacities of GA are enhanced while the diversity of population is maintained. In addition, the simplex search is used as a local search operator.

Particle Swarm Optimizer (PSO) originally developed by Kennedy and Eberhart [7] is inspired by social behavior of bird flocking or fish schooling. Gomes [11] utilized standard PSO to optimization of truss structures with dynamic constraints. Recently, Kaveh and Zolghadr [12] introduced democratic particle swarm optimization (DPSO) to mass minimization of trusses with frequency constraints. In this method, the exploration capability of standard PSO is improved by using the information produced by all of the eligible members of the swarm. As the name suggests, in the DPSO algorithm all of the better particles and some of the worse particles affect the new position of the particle under consideration.

Kaveh and Zolghadr [13] proposed a hybridized Charged System Search and Big Bang-Big Crunch algorithm (CSS$\mathrm{BBBC}$ ) with trap recognition capability for weight optimization of trusses on layout and size. This hybrid algorithm, improved the diversification properties of the standard CSS and uses BB$\mathrm{BC}$ algorithm to maintain an extra disturbance and to help the agents to leave the trap. Charged System Search (CSS) algorithm developed by Kaveh and Talatahari [8] is one of the most recent optimization algorithms. The method utilizes the governing Coulomb law from electrostatics and the Newtonian laws of mechanics to simulate the charged particles, which can affect each other based on their fitness values and their separation distances [8]. In addition, the Big Bang-Big Crunch (BB-BC) algorithm was developed by Erol and Eksin [9]. It is based on the theory of the evolution of the universe; namely, the Big Bang and Big Crunch theory. The BB-BC consists of two phase: Bigbang phase and Big-crunch phase. In the Big Bang phase, energy dissipation produces disorder and randomness is the main feature of this phase; whereas, in the Big Crunch phase, randomly distributed particles are drawn into an order [9].

Recently, a new population-based meta-heuristic algorithm based on the biogeography theory, namely Biogeography-Based Optimization (BBO), is introduced by Simon [14]. The biogeography theory, describes the geographical distribution of biological organisms. The framework of BBO inspired from mathematical models of biogeography which is developed by MacArthur and Wilson [15]. These mathematical models state that how species migrate between the islands (habitats) [14]. BBO is a successful heuristic search technique that has been successfully applied to global optimization of numerical functions [16, 17] and were used to solve numerous real-world optimization problems [14, 18, 19]. However, despite having a good exploitation ability, the standard BBO has the problem of premature convergence The main reason of poor exploration ability of standard $\mathrm{BBO}$ arises from it is migration operator. In the consecutive generations, the poor solutions are probabilistically updated by the migration operator, which shares the information of good solutions. After several generations, the current solutions finally converge to the same local optimum and the migration operator shares similar information among solutions. Although this similar information sharing leads to good exploitation capability, but it considerably decreases the exploration ability of BBO. In addition, the simple stochastic mutation operator of BBO may lead to revisiting non-productive regions of the search space.

As a kind of characteristic of non-linear systems, chaos is a bounded unstable dynamic behavior that exhibits sensitive dependence on initial conditions and includes infinite unstable periodic motions [2]. Chaos is a deterministic process with stochastic appearance exhibited by a deterministic nonlinear system. Due to the non-repetition of chaos, it can carry out overall searches at higher speeds than stochastic ergodic searches that depend on probabilities [21]. Chaotic sequences are very sensitive to the initial conditions and two quite different sequences can be generated by the two very close initial parameters. Recently, many researchers have used the idea of employing chaotic sequences during the optimization process of metaheuristics instead of random sequences, such as chaotic particle swarm optimization (CPSO) [22,23], chaotic differential evolution (CDE) [24] and chaotic harmony search (CHS) [25]. The choice of chaotic sequences is justified theoretically by their unpredictability, i.e., by their spread-spectrum characteristic and 
ergodic properties [25].

In the present study, the BBO is combined with the chaos theory to obtain a new optimization method called the Chaotic Biogeography-Based Optimization (CBBO) to size and shape optimization of truss structures with frequency constraints. In order to accelerate the convergence speed, two operators based on Chaos theory are developed, namely chaotic migration and mutation operators. The proposed migration operator employs logistic map function and a selection strategy for efficient information sharing between the habitats. Through this migration scheme, the exploration ability of the algorithm is increased and CBBO can quickly and accurately find an near-optimum solution. In addition, based on the ergodicity, symmetry and stochastic property of the improved logistic map function, we develop new mutation operator to increase the population diversity. A set of five well-known design examples are considered to validate the efficiency of the proposed method. The simulation results validate the superiority of the new method in obtaining optimal designs as compared with other methods.

The rest of the paper is organized as follows. Section 2 provides a mathematical description of the optimum design problem. In Section 3 the simple BBO and chaotic sequences are briefly described and then the proposed CBBO algorithm are presented and explained in detail. Five optimal design examples illustrating the efficiency of the proposed algorithm are covered in the Section 4. Finally, conclusions are presented in Section 5

\section{Mathematical description of the optimum design problem}

The main aim of layout and size optimization of a truss structure is to minimize the weight of the structure while satisfying some constraints on natural frequencies. In this class of optimization problems, cross-sectional areas and nodal coordinates are taken as design variables. The optimal design of a truss structure can be formulated as:

$$
\begin{aligned}
& \text { Find } X=\left[x_{1}, x_{2}, \ldots, x_{n}\right] \\
& \text { To minimize } W(X)=\sum_{i=1}^{m} \rho_{i} A_{i} L_{i}
\end{aligned}
$$

Subjected to:

$$
\begin{aligned}
g(X) & =\frac{\omega_{j}}{\omega_{j}^{*}}-1 \geq 0, \quad \text { for some natural frequencies } j \\
h(X) & =\frac{\omega_{k}}{\omega_{k}^{*}}-1 \leq 0, \quad \text { for some natural frequencies } k \\
x_{i}^{\min } & \leq x_{i} \leq x_{i}^{\max },
\end{aligned}
$$

Where $X$ is the vector containing the design variables, including both nodal coordinates and cross-sectional areas; $n$ is the number of design variables; $W(X)$ is the weight of the structure; $m$ is the number of members making up the structure; $\rho_{i}$ is the density of member $i ; A_{i}$ is the cross-sectional area of the member $i ; L_{i}$ is the length of the member $i$; $g(X)$ and $h(X)$ are the constraint violations for natural frequencies of the structure; $\omega_{j}$ and $\omega_{j}^{*}$ are the $j$ th natural frequency of the structure and corresponding lower limit, respectively; $\omega_{k}$ is the $k$ th natural frequency of the structure and $\omega_{k}^{*}$ is its upper bound; $x_{i}^{\min }$ and $x_{i}^{\max }$ are the lower and upper bounds of the $i$ th design variable, respectively.

Optimal design of truss structure should satisfy the above mentioned constraints. In this study, the constraints are handled by using a simple penalty function method, which can guide the unfeasible candidate solutions to move to the feasible regions of search space. Thus we define the fitness function for each solution candidates. The fitness function of solution candidate $X$ is defined as follow:

$$
\begin{gathered}
F_{\text {fitness }}=W(X) \times f_{\text {penalty }} \\
f_{\text {penalty }}=\left(1+\varepsilon_{1} \cdot \varphi\right)^{\varepsilon_{2}}, \quad \varphi=\sum_{i=1}^{q} \varphi_{i}
\end{gathered}
$$

Where $f_{\text {penalty }}$, is the penalty function represented by individual $X, q$ is the number of constraint violation and $\varphi$ is the penalty factor which is related to the violation of constraints. In order to obtain the values of $\varphi_{i}$ the natural frequencies of the structure are compared to the corresponding upper or lower bounds. For example for $j$ th frequency constraint, the penalty factor is calculated as follow:

$$
\left\{\begin{array}{cc}
\varphi_{j}=\left|\frac{\omega_{j}^{*}-\omega_{j}}{\omega_{j}^{*}}\right| & \text { for } \omega_{j}<\omega_{j}^{*} \\
\varphi_{j}=0 & \text { for } \omega_{j} \geq \omega_{j}^{*}
\end{array}\right.
$$

As it can be seen from Eq. (2), if the constraints are not violated, the value of the penalty function will be zero. In Eq. (3), the parameters $\varepsilon_{1}$ and $\varepsilon_{2}$ are selected considering the exploration and the exploitation rate of the search space. In this study $\varepsilon_{1}$ is taken as unity and $\varepsilon_{2}$ starts from 2 and gradually increases. The value of $\varepsilon_{2}$ for $t$ th iteration is calculated as follow:

$$
\varepsilon_{2}^{(t)}=\varepsilon_{2}^{(t-1)}+10^{-3} t
$$

\section{Optimization method}

\subsection{Biogeography-based optimization (BBO)}

BBO is a simple and efficient optimization algorithm originally proposed and shown effective for finding global optima for some optimization problems by Simon [14]. In fact, BBO is a population-based meta-heuristic algorithm motivated by migration behavior of species between the habitats, in which each habitat is a solution candidate for the optimization problem. In $\mathrm{BBO}$, the position of each habitat $\mathrm{H}$ in an $\mathrm{n}$-dimensional search space is represented by suitability index variables (SIVs), which is an n-dimensional vector The fitness value of each habitat is demonstrated by Habitat Suitability Index (HSI).

Habitats with a high HSI tend to have a large number of species, while those with a low HSI have a small number of species [14]. The two main operators of this algorithm are $\mathrm{Mi}$ gration and Mutation operators 
In the $\mathrm{BBO}$ approach, the emigration and immigration process is done by migration operator between good and poor habitats to share information about the appropriate habitats which are possible solutions for optimization problem. This information sharing depends on the immigration rate $\lambda$ and emigration rate $\mu$ of each habitat, which are functions of the number of species in the habitat. These can be calculated by Eq. (6) and Eq. (7), as follows [14]:

$$
\begin{gathered}
\lambda_{k}=I\left(1-\frac{K}{S_{\max }}\right) \\
\mu_{k}=E\left(\frac{K}{S_{\text {max }}}\right)
\end{gathered}
$$

Where $I$ is the maximum possible immigration rate; $E$ is the maximum possible emigration rate; $K$ is the number of species of the $k$ th habitat and $S_{\max }$ is the maximum number of species. Fig. 1 illustrates a linear migration model for the case of $E=I$. As it can be seen from Fig. 11, the habitat which has few species (poor solution, low HSI) like $S_{1}$ has a low emigration rate and a high immigration rate. This means that, the habitat with low HSI have a greater chance to take information about the good habitats. On the other hand, the habitat which has more species (good solution, high HSI) like $S_{2}$ has a low immigration rate and a high emigration rate. In this way, the habitat with high HSI tends to share its good information among the habitats. In addition, the habitat with medium HSI, like point $S_{0}$, both immigration and emigration rates are equal, in which the probability of taking or giving information from or to other habitats is equal. The point $S_{0}$ is the equilibrium number of species. The migration operator can be described as follow:

$$
H_{i}(S I V) \longleftarrow H_{j}(S I V)
$$

Where $H_{i}$ and $H_{j}$ are the immigrating and emigrating habitats, respectively. These habitats, is the probabilistically selected habitats based on the immigration and emigration rates. Fig. 2 depicts the migration producer of $\mathrm{BBO}$ algorithm.

After migration operator, $\mathrm{BBO}$ utilizes the mutation operator to increase the population diversity. The mutation operator is a probabilistic operator that modifies a habitat's SIV randomly based on mutation rate pMutate that is related to the habitat probability. The mutation rate pMutate is calculated as follows:

$$
\text { pMutate }=m_{\max }\left(\frac{1-P_{i}}{P_{\max }}\right)
$$

Where $m_{\max }$ is a user-defined parameter and $P_{\max }=\max \left\{P_{i}\right\}$. The complete details for the calculation of $P_{\text {max }}$ and $P_{i}$ can be found in [14]. According Eq. (9), each habitat has a different chance to mutate, but in this paper the same mutation probability are considered for all habitats. The mutation operator of BBO algorithm can be described as Fig. 3 .

Another feature of BBO is that some habitats with high HSI (elites) selected by the parameter of KeepRate to keep elites from one generation to the next. It means that, the new habitats of current iteration combined with some elites from prior iteration. After combining habitats, habitats with high HSI are selected to the formation of new population. In this study, the value of parameter KeepRate is set to 0.1 for all numerical examples. For example, when the number of habitats is 50, five habitats with high HSI are selected to keep.

\subsection{Chaotic sequence}

Chaos is a deterministic process with stochastic appearance exhibited by a deterministic nonlinear system in which small changes in the parameters or the starting values for the data lead to different future behaviors, such as stable fixed points, periodic oscillations, bifurcations, and ergodicity [26]. Recently, chaotic sequences are used in place of random sequences during the optimization process. There are various one-dimensional chaotic maps to generate chaotic sequences such as Logistic map, Kent map, Bernoulli shift map, Sine map and Circle map. Logistic map is one of the most used chaotic maps in literature. It has been brought to the attention of researchers by May [27] which often cited as an example of how complex behavior can arise from simple dynamic systems. The simple Logistic chaotic map is described as follows:

$$
y_{t+1}=\beta y_{t}\left(1-y_{t}\right), \quad t=1,2, \ldots ; \quad y_{0} \in(0,1)
$$

Where $\beta$ is the control parameter, $y_{t}$ is a chaotic variable in iteration $t$ It can be mathematically prove that the system with initial condition $y_{0} \notin(0,0.25,0.5,0.75)$, is entirely in chaotic status when $\beta=4$ Fig. 4 shows the ergodic property and the probability distribution of the Logistic map function considering the initial value of $y_{0}=0.35$ and 3000 iterations. By setting $y_{t}=\left(z_{t}+1\right) / 2$ in Eq. (8), the improved chaotic logistic map with symmetrical region $(-1,1)$ is expressed as Eq. (9] [28]:

$$
z_{t+1}=1-2 z_{t}^{2}, \quad t=1,2, \ldots ; \quad z_{t} \epsilon(-1,1)
$$

Fig. 5 shows the ergodic property and the probability distribution of the improved logistic map function considering the initial value of $z_{0}=0.35$ and 3000 iterations.

\subsection{Chaotic biogeography-based optimization (CBBO)}

As mentioned before, the basic BBO, which has been widely used to solve various scientific and engineering optimization problems, employs simple migration and mutation operators. However, such simple operators may lead to some disadvantages such as a low exploration ability and premature convergence. In Eq. (8), the immigrating habitat updated by simply replacing one of the SIV of emigrating habitat randomly, which often implies a rapid loss of diversity in the population. On the other hand, the purely random mutation operator of BBO may lead to revisiting non-productive regions of the search space which lead to long computing time. To cope with these disadvantages of BBO, 


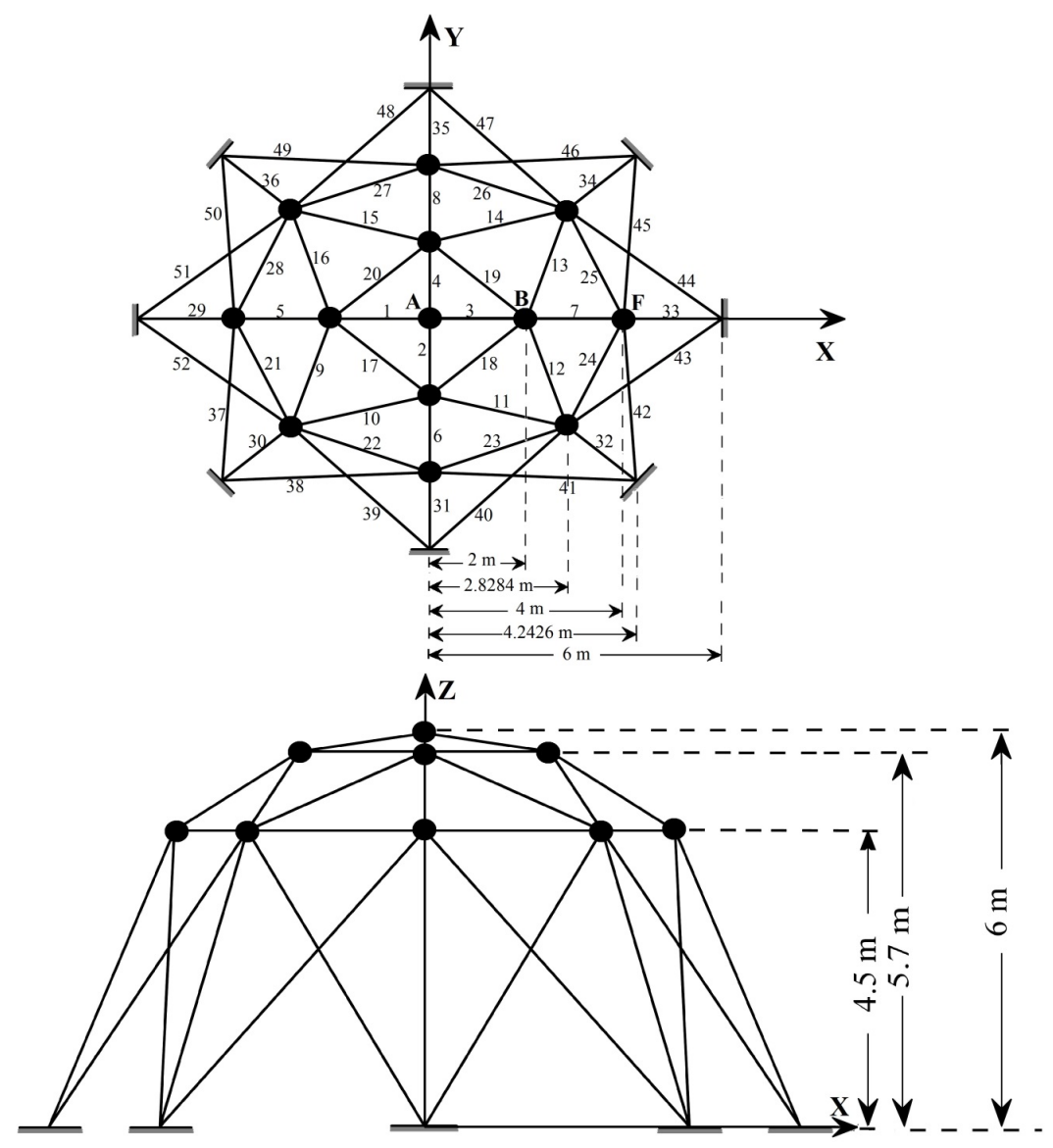

Fig. 1. The simple linear migration model. Emigration and immigration rates for case $E=I$.

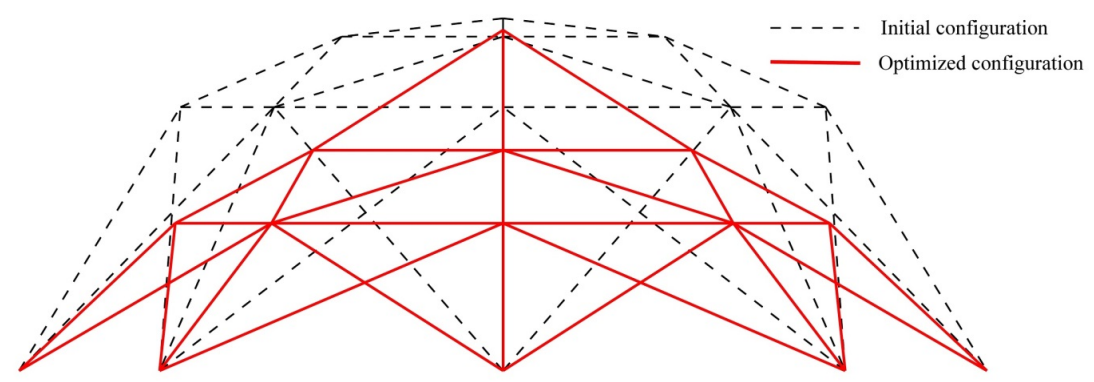

Fig. 2. The migration operator of BBO. 


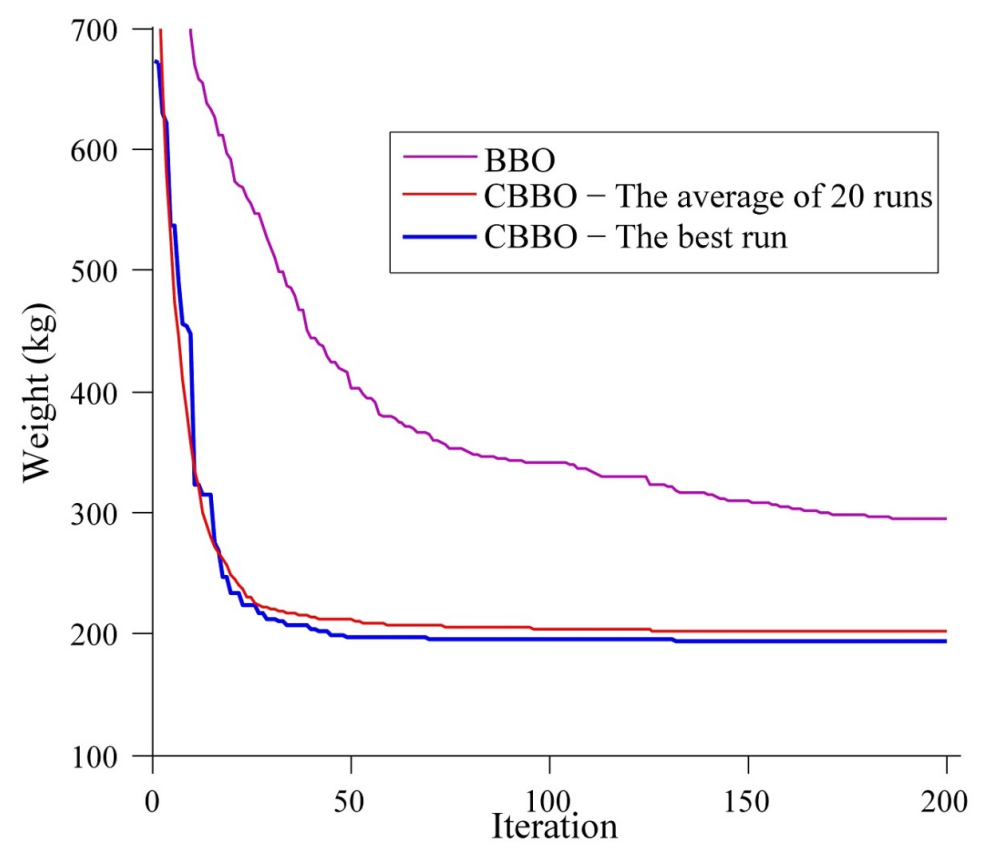

Fig. 3. The mutation operator of BBO.
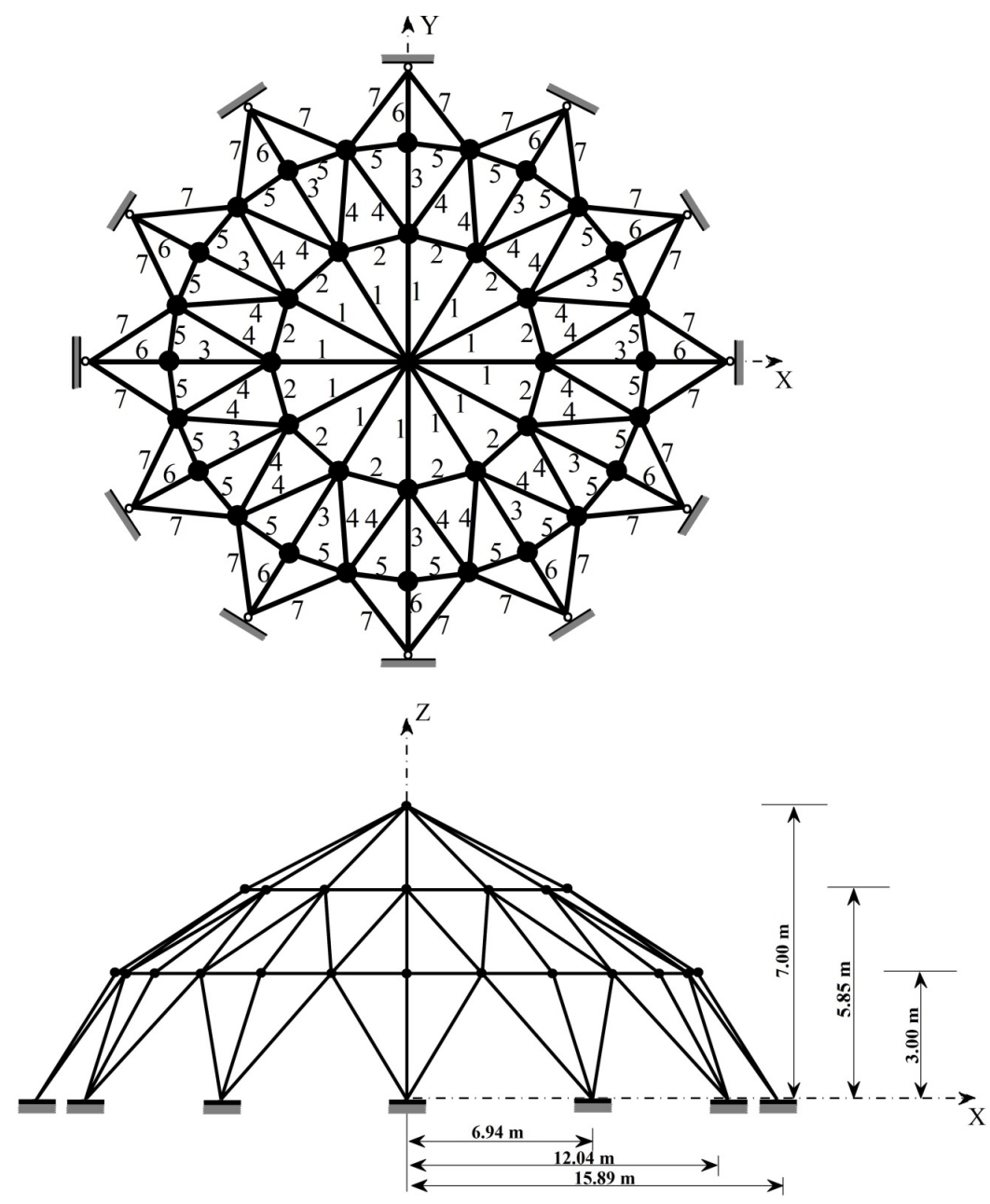

Fig. 4. The ergodic property and the probability distribution of the logistic map function with the initial value of $y_{0}=0.35$ and 3000 iterations. 


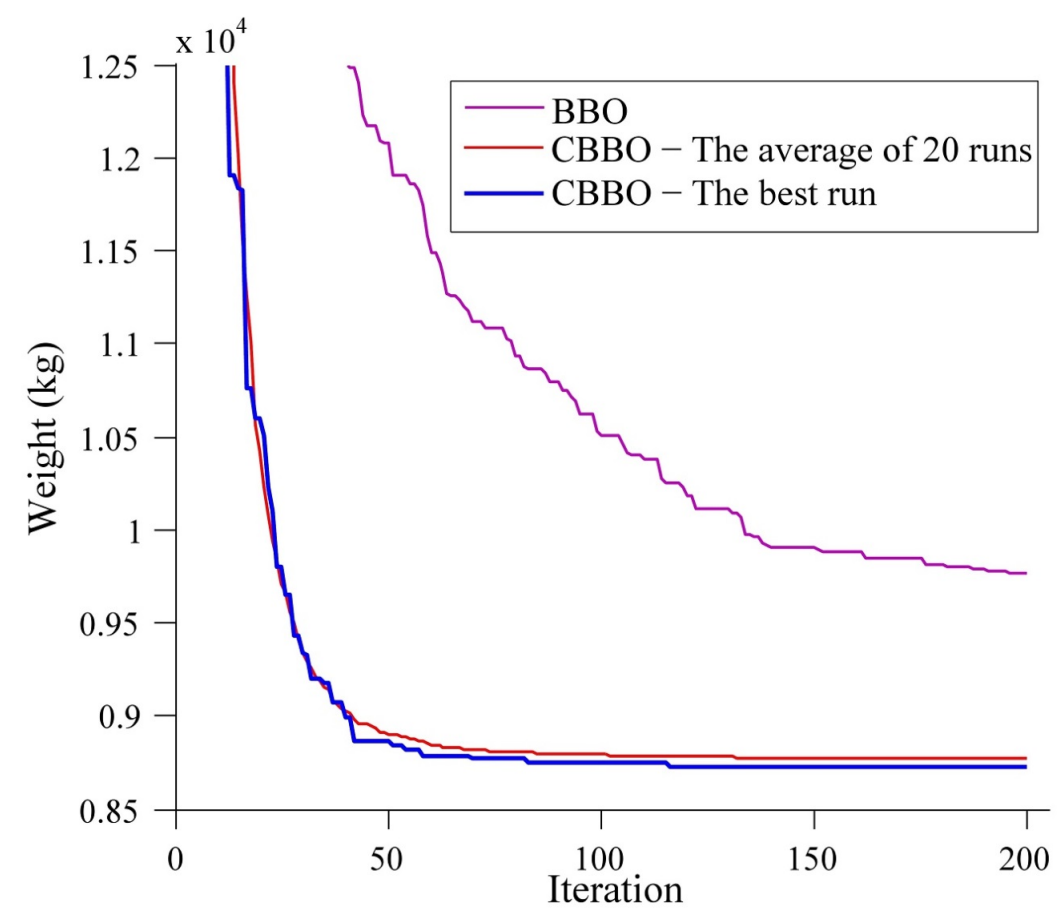

Fig. 5. The ergodic property and the probability distribution of the improved logistic map function with the initial value of $z_{0}=0.35$ and 3000 iterations.

A Chaotic Biogeography-Based optimization (CBBO) based on new chaotic migration and mutation operators is proposed

During the information sharing process of the migration operator, some habitats may be trapped into local optimum and it is necessary to exchange the solution space information among the whole population, efficiently Thus, the migration operator should provide a variety of information about the population between the habitats. In order to get a better performance including the better solution and convergence speed, the new logistic map based migration operator is described as follows:

$$
\begin{aligned}
& H_{i}(k)=H_{i}(k)+c_{1} \times y_{t}^{(1)} \times \\
& \left(H_{j}(k)-H_{i}(k)\right)+c_{2} \times y_{t}^{(2)} \times\left(H_{l}(k)-H_{i}(k)\right)
\end{aligned}
$$

Where $H_{i}$ is the immigrating habitat, $H_{j}$ and $H_{l}$ are the emigrating habitats, $c_{1}$ and $c_{2}$ are two positive constants which adjust the influence degree of two selected emigrating habitats and $y_{t}$ is the chaotic variable between $(0,1)$ generated by Eq. 10 It is important to note that, $y_{t}^{(1)}$ and $y_{t}^{(2)}$ are two different chaotic sequences with different initial value $\left(y_{0}\right)$ generated by Eq. (10). The initial values for chaotic sequences are randomly selected between 0 and 1 , except points $(0,0.25,0.5,0.75)$ Here the two emigrating habitats $H_{j}$ and $H_{l}$ are selected probabilistically based on emigration rates At each iteration cycle, the $k$ th variable of position of habitats is updated by Eq. (12). Note that, whenever the updated position of a habitat goes beyond its lower or upper bound, the habitat will take the value of its corresponding lower or upper bound.

The proposed migration operator appears to be more useful because it takes into consideration two different habitats. As mentioned before, the emigrating habitats are randomly selected based on their emigrating rates, and the emigration rates are directly proportional to the HSI values (fitness values). In fact, according to Eq. (12), all of the better and worse habitats affect the new position of the habitat under consideration, but the habitats with high HSI have a high chance to affect the new position. This migration scheme can improve the exploration ability of the algorithm and alleviate premature convergence.

After migration operator, each variable of a habitat is mutated according to the mutation probability (pMutation). As mentioned before, standard BBO uses a purely random generation to mutate habitats, which leads to revisiting non-productive regions of the search space and often exhibit unacceptably slow convergence rate. In order to reduce the effects of purely random mutation and to prevent the local trapping of the algorithm, the new improved logistic map based mutation operator for $k$ th variable of $i$ th habitat is described as follow:

$$
H_{i}(k)=H_{i}(k)+z_{t} \times \alpha \times\left(H_{\max }(k)-H_{\min }(k)\right)
$$

Where $z_{t}$ is the chaotic variable between $(-1,1)$ generated by Eq. (11), $\alpha$ is the user defined parameter, $H_{\text {max }}(k)$ showing the upper bound and $H_{\min }(k)$ indicating the lower bound for variable $k$.

It seems that the values of low mutation probabilities ( $p M u$ tation) is appropriate values and high values of this parameter may not be suitable. This parameter is usually set as too small to get good results. In this study, the value of mutation probability (pMutation) is considered as 0.1 for all experiments.

The value of $\alpha$ controls search length of the mutation operator. A small length may be inefficient in exploring different regions 
of the search space and therefore unsuccessful at improving the search quality. On the other hand, with a longer length, the mutation operator may cause revisiting non-productive regions unnecessarily.

In order to better explain the algorithm, the detailed steps of CBBO can be summarized as below:

Step 1: define the optimization problem, set the initial values for chaotic sequences $\left(z_{0}\right.$ and $\left.y_{0}\right)$ and initialize the CBBO parameters:

- pMutation: the mutation probability;

- KeepRate: parameter to keep elites from prior iteration to the next;

- $N_{H}$ : the number of habitats (population size);

- $c_{1}$ and $c_{2}$ : the parameters of migration operator;

- $\alpha$ : the parameter of mutation operator;

As it mentioned previously, the value of parameters pMutation and KeepRate are set to 0.1 in all design examples So, in CBBO algorithm, $N_{H} c_{1}, c_{2}$ and $\alpha$ are the internal parameters that should be controlled.

Step 2: Initialize habitats with randomly generated $N_{H}$ habitats and evaluate fitness (HSI) for each habitat.

Step 3: For each individual, map the HSI to the number of species and calculate the immigration rate $\lambda$ and the emigration rate $\mu$ for each habitat.

Step 4: Update the position of each habitat by the migration and mutation operators and evaluate them.

Step 5: Combine the elites from previous iteration with new habitats and select $N_{H}$ habitats with high HSI among them.

Step 6: Repeat from Steps 3 to 6 till the termination criterion is met.

For other algorithms and comparative studies the interested reader may refer to $[31-33]$.

\section{Design examples}

In this section, five design examples are studied to assess the performance of the CBBO approach for the optimization of truss structures with natural frequency constraints: 10-bar planar truss, the simply supported 37-bar planar truss, 52-bar space truss, 120-bar dome truss and 200-bar planar truss. Examples 1,4 and 5 focus on optimal design of truss structures considering only size variables, while examples 2 and 3 discuss the weight minimization of truss structures considering both size and shape variables together. The performance of the CBBO may depend on some internal parameters such as number of habitats $N_{H}$, constant parameters $c_{1}, c_{2}$ and $\alpha$ In each design example, sensitivity analysis was performed for internal parameters of the $\mathrm{CBBO}$ algorithm to investigate how the $\mathrm{CBBO}$ is affected by these parameters and the best combination of them obtained. The sensitivity analyses are carried out on the CBBO using different values of population size $\left(N_{H}\right)$ and three constant parameters $\left(c_{1} c_{2}\right.$ and $\left.\alpha\right)$. For design examples 1 through 4 , three settings are considered for $N_{H}$ parameter and two settings for $C_{1} C_{2}$ and $\alpha$ parameters That is, $N_{H} \in\{20,30,40\}$, $\left(c_{1} c_{2}\right) \in\{1,2\}$ and $\alpha \in\{0.05,0.15\}$ For last design example the case of $N_{H}=50$ is added to parameter setting cases. The proposed method were run 10 times with random initial population for each case of parameter combination and the best, worst, mean structural weights and standard deviations are obtained.

In order to assess the effect of different initial solution vector (i.e. initial population and initial values of $y_{0}$ and $z_{0}$ ) on the final result and because of the random nature of the algorithm, each design example are independently optimized 20 times with selected parameters by sensitivity analysis. The best result, average and the standard deviation of 20 independent runs are given in the tables.

Each run stops when the maximum iterations are reached. In all design examples, the maximum iterations are set to 200. In order to show effectiveness of the proposed algorithm, $\mathrm{CBBO}$ is compared with both standard BBO algorithm and other optimization methods in literature. It is worth mentioning that the same parameters are used for standard BBO and CBBO algorithms in all design examples. The CBBO and BBO implementation was coded in Matlab program

\section{Example 1. A 10-bar planar truss}

The first design example is the size optimization of a 10bar planar truss with fixed configuration shown in Fig. 6. The Young's modulus and material density of truss members are $6.89 \times 10^{10} \mathrm{~kg} / \mathrm{m}^{2}$ and $2770.0 \mathrm{~kg} / \mathrm{m}^{3}$, respectively. As seen in Fig. 6 a non-structural mass of $454.0 \mathrm{~kg}$ are attached for all free nodes. The lower and upper bounds for the cross-sectional areas are specified as $0.645 \mathrm{~cm}^{2}$ and $50 \mathrm{~cm}^{2}$, respectively. In this design example, the three natural frequency constraints are considered as: $\omega_{1} \geq 7 \mathrm{~Hz}, \omega_{2} \geq 15 \mathrm{~Hz}, \omega_{3} \geq 20 \mathrm{~Hz}$. It should be noted that in some references the Young's modulus of truss members is given as $6.98 \times 10^{10} \mathrm{~kg} / \mathrm{m}^{2}$. So, for a fair comparison, two cases are considered as: $E=6.89 \times 10^{10} \mathrm{~kg} / \mathrm{m}^{2}$ (Case 1) and $E=6.98 \times 10^{10} \mathrm{~kg} / \mathrm{m}^{2}$ (Case 2 ).

The results of the sensitivity analysis carried out to find the best combination of the parameters for $\mathrm{CBBO}$ are presented in Tab. 1. It is apparent from Tab. 1 1 that $N_{H}=30, c_{1}=1, c_{2}=1$ and $\alpha=0.05$ are the relatively best case of parameter settings for Case 1 of this example. The results obtained by standard $\mathrm{BBO}$ and $\mathrm{CBBO}$ for two cases are summarized in Tab. 2] and compared to those reported previously.

From Tab.2, in Case 1, it can be concluded that CBBO gives lightest design as compared to the results obtained by Grandhi and Venkayya [2], Sedaghati and et al. [3], Wang et al. [5] and Lingyun et al. [10], but slightly heavier design than DPSO [12] method. Also it is clear that the values of mean weight and standard deviation for $\mathrm{CBBO}$ are relatively less than other methods.

In Case 2, the results obtained by the standard $\mathrm{BBO}$ and 


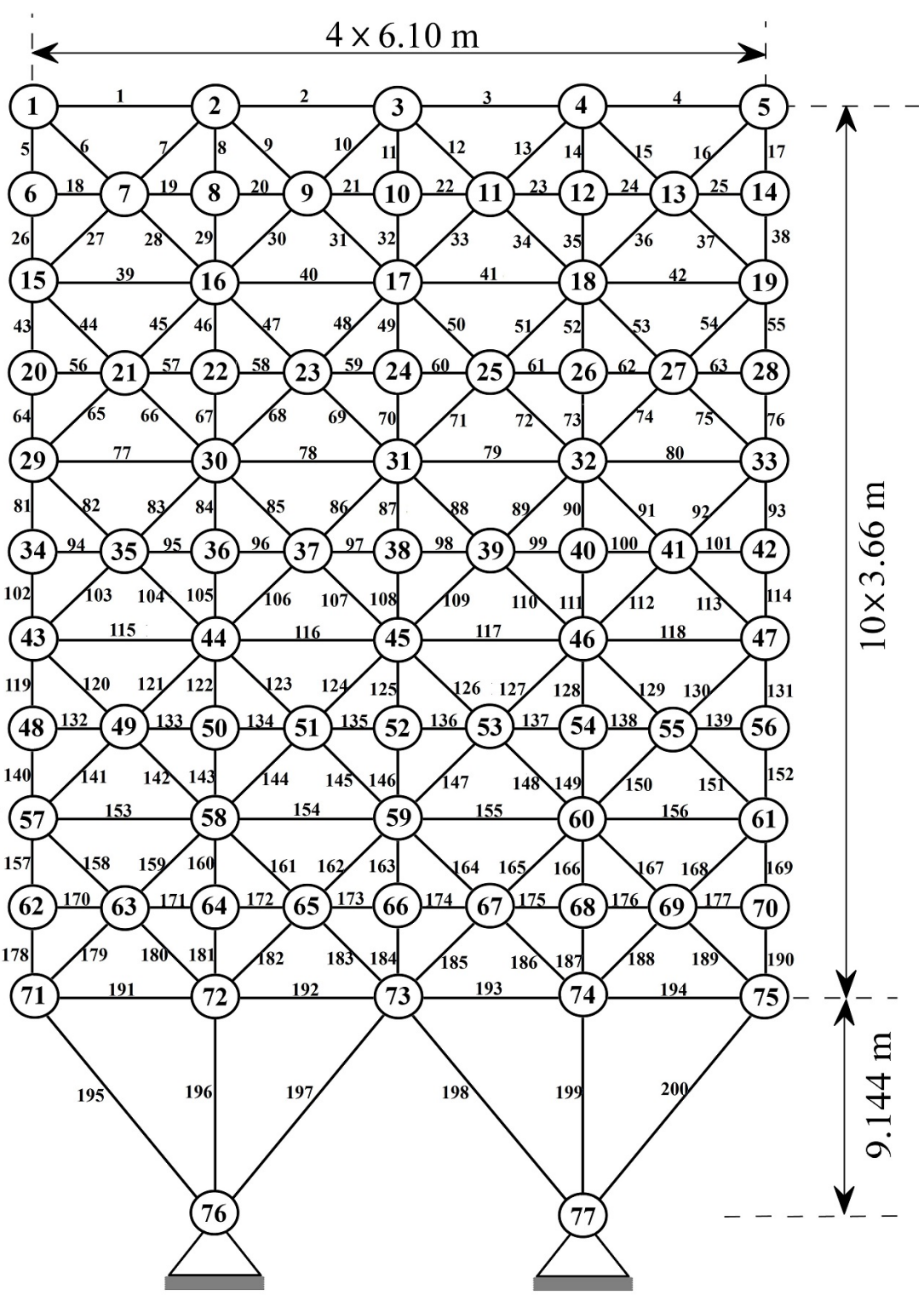

Fig. 6. Schematic of the planar 10-bar truss structure.

Tab. 1. Results of sensitivity analysis carried out to find the best combination of the parameters of CBBO for the planar 10-bar truss problem (Case 1).

\begin{tabular}{ccccccccc}
\hline & \multicolumn{7}{c}{ Parameters } & \multicolumn{7}{c}{ Weight $(\mathrm{kg})$} \\
\hline Case & $N_{H}$ & $c_{1}$ & $c_{2}$ & $\alpha$ & Best & Mean & Std & Worst \\
\hline 1 & 20 & 1 & 1 & 0.05 & 533.68 & 539.21 & 3.79 & 545.77 \\
2 & 20 & 2 & 1 & 0.05 & 535.75 & 542.58 & 4.12 & 547.47 \\
3 & 20 & 1 & 2 & 0.05 & 534.41 & 540.55 & 4.21 & 547.72 \\
4 & 30 & 1 & 1 & 0.05 & 532.47 & 535.49 & 3.49 & 541.55 \\
5 & 30 & 2 & 1 & 0.05 & 532.96 & 538.52 & 3.85 & 542.84 \\
6 & 30 & 1 & 2 & 0.05 & 534.88 & 539.84 & 3.40 & 543.49 \\
7 & 40 & 1 & 1 & 0.05 & 533.08 & 535.89 & 3.11 & 542.37 \\
8 & 40 & 2 & 1 & 0.05 & 533.73 & 537.32 & 3.10 & 542.12 \\
9 & 40 & 1 & 2 & 0.05 & 534.81 & 541.51 & 3.46 & 546.52 \\
10 & 20 & 1 & 1 & 0.5 & 534.42 & 538.45 & 3.50 & 543.41 \\
11 & 20 & 2 & 1 & 0.5 & 538.21 & 546.88 & 7.61 & 560.15 \\
12 & 20 & 1 & 2 & 0.5 & 537.38 & 546.37 & 6.94 & 561.01 \\
13 & 30 & 1 & 1 & 0.5 & 533.80 & 537.07 & 3.26 & 545.24 \\
14 & 30 & 2 & 1 & 0.5 & 537.54 & 542.82 & 3.48 & 549.04 \\
15 & 30 & 1 & 2 & 0.5 & 535.1 & 544.39 & 4.94 & 552.69 \\
16 & 40 & 1 & 1 & 0.5 & 533.91 & 538.02 & 3.81 & 545.34 \\
17 & 40 & 2 & 1 & 0.5 & 539.74 & 544.24 & 3.56 & 550.93 \\
18 & 40 & 1 & 2 & 0.5 & 535.33 & 541.39 & 4.27 & 548.29 \\
\hline
\end{tabular}


Tab. 2. Optimized designs $\left(\mathrm{cm}^{2}\right)$ obtained for the 10-bar planar truss problem (the optimized weight does not include the added masses).

\begin{tabular}{|c|c|c|c|c|c|c|c|c|c|c|c|c|c|}
\hline & Case 1 & & & & & & & Case 2 & & & & & \\
\hline $\begin{array}{c}\text { Design } \\
\text { vari- }\end{array}$ & $\begin{array}{l}\text { Gran- } \\
\text { dhi and } \\
\text { Ven- }\end{array}$ & $\begin{array}{l}\text { Seda- } \\
\text { ghati et }\end{array}$ & $\begin{array}{l}\text { Wang } \\
\text { et al. }\end{array}$ & $\begin{array}{c}\text { Lin- } \\
\text { gyun et }\end{array}$ & $\begin{array}{c}\text { Kaveh } \\
\text { and } \\
\text { Zol- }\end{array}$ & Prese & work & Gomes & Kaver & and Zolghadr & $r$ & Prese & work \\
\hline & & & & NHPGA & DPSO & BBO & CBBO & PSO & CSS & $\begin{array}{c}\text { En- } \\
\text { hanced } \\
\text { CSS }\end{array}$ & $\begin{array}{l}\text { CSS- } \\
\text { BBBC }\end{array}$ & BBO & CBBO \\
\hline$A_{1}$ & 36.584 & 38.245 & 32.456 & 42.234 & 35.944 & 42.220 & 35.897 & 37.712 & 38.811 & 39.569 & 35.274 & 41.524 & 34.895 \\
\hline$A_{2}$ & 24.658 & 9.916 & 16.577 & 18.555 & 15.530 & 16.336 & 15.071 & 9.959 & 9.031 & 16.740 & 15.463 & 16.94 & 14.359 \\
\hline$A_{3}$ & 36.584 & 38.619 & 32.456 & 38.851 & 35.285 & 31.854 & 35.171 & 40.265 & 37.099 & 34.361 & 32.110 & 35.048 & 34.946 \\
\hline$A_{4}$ & 24.658 & 18.232 & 16.577 & 11.222 & 15.385 & 18.418 & 14.804 & 16.788 & 18.479 & 12.994 & 14.065 & 8.3278 & 14.541 \\
\hline$A_{5}$ & 4.167 & 4.419 & 2.115 & 4.783 & 0.648 & 0.734 & 0.645 & 11.576 & 4.479 & 0.645 & 0.645 & 3.765 & 0.645 \\
\hline$A_{7}$ & 27.032 & 20.097 & 22.810 & 21.049 & 23.610 & 21.757 & 24.094 & 25.308 & 20.842 & 26.182 & 24.046 & 24.932 & 23.818 \\
\hline$A_{8}$ & 27.032 & 24.097 & 22.810 & 20.949 & 23.599 & 23.581 & 24.056 & 21.613 & 23.023 & 21.260 & 24.340 & 21.182 & 24.057 \\
\hline$A_{9}$ & 10.346 & 13.890 & 17.490 & 10.257 & 13.135 & 12.771 & 12.986 & 11.576 & 13.763 & 11.766 & 13.343 & 12.229 & 12.402 \\
\hline$A_{10}$ & 10.346 & 11.452 & 17.490 & 14.342 & 12.357 & 12.104 & 12.358 & 11.186 & 11.414 & 11.392 & 13.543 & 13.256 & 12.646 \\
\hline $\begin{array}{c}\text { Weight } \\
(\mathrm{kg})\end{array}$ & 594 & 537.01 & 553.8 & 542.75 & 532.39 & 541.32 & 532.47 & 537.98 & 531.95 & 529.25 & 529.09 & 535.73 & 524.60 \\
\hline Mean & & & & & & & & & & & & & \\
\hline $\begin{array}{c}\text { weight } \\
(\mathrm{kg})\end{array}$ & $\mathrm{N} / \mathrm{A}$ & $\mathrm{N} / \mathrm{A}$ & $\mathrm{N} / \mathrm{A}$ & 552.447 & 537.8 & 553.57 & 537.01 & 540.89 & 536.39 & 538.53 & $\mathrm{~N} / \mathrm{A}$ & 551.76 & 527.23 \\
\hline $\begin{array}{l}\text { Standaro } \\
\text { devia- } \\
\text { tion } \\
(\mathrm{kg})\end{array}$ & $\mathrm{N} / \mathrm{A}$ & $\mathrm{N} / \mathrm{A}$ & $\mathrm{N} / \mathrm{A}$ & 4.864 & 4.02 & 7.64 & 3.90 & 6.84 & 3.32 & 5.97 & $\mathrm{~N} / \mathrm{A}$ & 11.92 & 2.52 \\
\hline
\end{tabular}


$\mathrm{CBBO}$ are compared with those reported in the literature like PSO [11], CSS, Enhanced CSS and CSS-BBBC [13]. It is observed from Tab. 2 that the CBBO significantly outperforms other methods in terms of the values of best, mean and standard deviation of structural weight. In addition, the mean weight obtained by $\mathrm{CBBO}$ is also lighter than the best weights presented by other methods, which shows its accomplishment in reaching the near-optimal design. Moreover, it should be noted that Kaveh and Zolghadr [12] obtained a weight of $524.70 \mathrm{~kg}$ for Case 2 which is heavier than the weight obtained by CBBO.

The natural frequencies evaluated at the optimum designs for each case are given in Tab. 3. In addition, the convergence behaviors of the best solution and the average of 20 independent runs for each case are shown in Fig. 7. It is clear from Fig. 7 that the $\mathrm{CBBO}$ converges to the near-optimum solution after 80 iterations without any abrupt oscillations, while standard $\mathrm{BBO}$ method converges to local solution as a result of suffering from the shortcoming of premature convergence The CBBO reached the best result in iterations 120 and 113 for Case 1 and Case 2, respectively.

\section{Example 2. A simply supported 37-bar planar truss}

The second design example deals with the size and shape optimization of a simply supported 37-bar planar truss shown in Fig. 8. The Young's modulus and material density of truss members are $2.1 \times 10^{11} \mathrm{~N} / \mathrm{m}^{2}$ and $7800 \mathrm{~kg} / \mathrm{m}^{3}$, respectively. As seen in Fig. 8, a non-structural mass of $10 \mathrm{~kg}$ are attached for all free nodes. The constant rectangular cross-sectional areas of $4 \times 10^{-3} \mathrm{~m}^{2}$ are specified for all members of the lower chord and the cross-sectional areas of other members are considered as design variables. In addition, the y-coordinate of upper nodes are taken as layout variables considering symmetry and their vertical position must not exceed $\pm 1.5 \mathrm{~m}$ Thus, the optimization problem includes 19 design variables ( 5 for shape variables and 14 for size variables). Furthermore, the structure is subject to the first three frequency constraints as: $\omega_{1} \geq 20 \mathrm{~Hz}, \omega_{2} \geq 40 \mathrm{~Hz}$, $\omega_{3} \geq 60 \mathrm{~Hz}$.

The results of the sensitivity analysis carried out to find the best combination of parameters for CBBO are reported in Tab. 4 Once again, it can be seen from Tab. 4 that the minimum structural weight is obtained for $N_{H}=30, c_{1}=1 c_{2}=1$ and $\alpha=0.05$

In Tab. 5, the results obtained by the $\mathrm{CBBO}$ and $\mathrm{BBO}$ are compared with those reported in the literature like NHGA [10], PSO [11], CSS, enhanced CSS [29] and DPSO [12]. From this table, it can be observed that CBBO significantly outperforms other methods in terms of the values of best, mean and standard deviation, which shows its stability in reaching the optimal weight of the structure during 20 independent runs. It is evident from Tab. 5 that the structural weight and standard deviation of 20 independent runs for the CBBO are $360.29 \mathrm{~kg}$ and $0.67 \mathrm{~kg}$, respectively, which are much less than the other optimization algorithms. Also, the natural frequencies obtained at the optimum designs are presented in Tab. 6
Fig. 9 compares the optimized layout with the initial configuration of the structure.

The convergence diagrams of the best solution and the average of 20 independent runs are presented in Fig. 10. As seen, the convergence rates of the best run and the average of 20 independent runs are close together which represents smaller value of the standard deviation.

\section{Example 3. A 52-bar space truss}

A 52-bar space truss shown in Fig. 11 is the third design example. The Young's modulus and material density of truss members are $2.1 \times 10^{11} \mathrm{~kg} / \mathrm{m}^{2}$ and $7800 \mathrm{~kg} / \mathrm{m}^{3}$, respectively. A non-structural mass of $50 \mathrm{~kg}$ are attached for all free nodes. As seen in Tab. 7, the elements of the structure are categorized in 8 groups with respect to symmetry. The coordinates of all free nodes are taken as design variables considering symmetry and their position movements must not exceed $\pm 2 \mathrm{~m}$ in $\mathrm{x}$ and $\mathrm{z}$ directions. The lower and upper bounds for the cross-sectional areas are specified as $1 \mathrm{~cm}^{2}$ and $10 \mathrm{~cm}^{2}$, respectively. Therefore, the optimization problem includes 13 design variables (5 shape variables and 8 size variables). Furthermore, the structure is subject to the first two frequency constraints as: $\omega_{1} \leq 15.916 \mathrm{~Hz}$, $\omega_{2} \geq 28.648 \mathrm{~Hz}$.

Again, Tab. 8 presents the results of the sensitivity analysis carried out to find the best combination of parameters for CBBO. The best optimal structural weight is obtained for $N_{H}=40, c_{1}=2, c_{2}=1$ and $\alpha=0.05$.

The optimal nodal coordinates and cross-sectional areas obtained by the $\mathrm{CBBO}, \mathrm{BBO}$ and the other optimization methods recently published in literature are reported in Tab.9 It is quite evident that $\mathrm{CBBO}$ gives the lightest design than all other techniques in the literature based on Tab. 9. From Tab. 9, it can be concluded that $\mathrm{CBBO}$ gives small mean weight as compared to CSS [29], Enhanced CSS [29], CSS-BBBC [13] PSO [11], NHGA [10] and Lin et al. [34], but slight large mean weight when compared with the DPSO [12] method. However, it should be noted that the $\mathrm{CBBO}$ produces much smaller overall standard deviation than all other methods. Also, the natural frequencies obtained at the optimum designs are presented in Tab. 10.

Tab. 11 compares the optimized shape with the initial layout of the structure. In addition, the convergence characteristics of the CBBO and BBO are shown in Tab. 12

\section{Example 4. A 120-bar dome truss}

The fourth design example is the size optimization of a 120bar dome truss shown in Fig. 14. The members of the structure are divided into 7 groups using symmetry as shown in Fig. 14 The minimum and maximum cross-sectional area for each group of members is $1 \mathrm{~cm}^{2}$ and $129.3 \mathrm{~cm}^{2}$, respectively. The Young's modulus and material density of truss members are $2.1 \times 10^{11} \mathrm{~kg} / \mathrm{m}^{2}$ and $7971.810 \mathrm{~kg} / \mathrm{m}^{3}$, respectively. Nonstructural masses are attached to all free nodes as follows: $3000 \mathrm{~kg}$ at node one, $500 \mathrm{~kg}$ at nodes 2 through $13 \mathrm{~kg}$ and $100 \mathrm{~kg}$ at the rest of the nodes. Furthermore, the structure is subject to the first two frequency constraints as: $\omega_{1} \geq 9 \mathrm{~Hz}, \omega_{2} \geq 11 \mathrm{~Hz}$. 
Tab. 3. Natural frequencies $(\mathrm{Hz})$ evaluated at the optimized designs for the 10-bar planar truss.

\begin{tabular}{|c|c|c|c|c|c|c|c|c|c|c|c|c|c|}
\hline & Case 1 & & & & & & & Case 2 & & & & & \\
\hline $\begin{array}{c}\text { Fre- } \\
\text { quency }\end{array}$ & $\begin{array}{l}\text { Gran- } \\
\text { dhi and } \\
\text { Ven- }\end{array}$ & $\begin{array}{c}\text { Seda- } \\
\text { ghati et }\end{array}$ & $\begin{array}{l}\text { Wang } \\
\text { et al. }\end{array}$ & $\begin{array}{l}\text { Lin- } \\
\text { gyun et }\end{array}$ & $\begin{array}{c}\text { Kaveh } \\
\text { and } \\
\text { Zol- }\end{array}$ & Prese & work & Gomes & Kaveh & and Zolghadr & $r$ & Preser & work \\
\hline & & & & NHPGA & DPSO & BBO & CBBO & PSO & CSS & $\begin{array}{c}\text { En- } \\
\text { hanced } \\
\text { CSS }\end{array}$ & $\begin{array}{l}\text { CSS- } \\
\text { BBBC }\end{array}$ & BBO & CBBO \\
\hline 1 & 7.059 & 6.992 & 7.011 & 7.008 & 7.000 & 7.000 & 7.000 & 7.000 & 7.000 & 7.000 & 7.000 & 7.001 & 7.000 \\
\hline 2 & 15.895 & 17.599 & 17.302 & 18.148 & 16.187 & 16.473 & 16.179 & 17.786 & 17.442 & 16.238 & 16.119 & 16.945 & 16.166 \\
\hline 3 & 20.425 & 19.973 & 20.001 & 20.000 & 20.000 & 20.042 & 20.004 & 20.000 & 20.031 & 20.000 & 20.075 & 20.040 & 20.001 \\
\hline 4 & 20.425 & 19.977 & 20.100 & 20.508 & 20.021 & 20.585 & 20.091 & 20.063 & 20.208 & 20.361 & 20.457 & 20.435 & 20.012 \\
\hline 5 & 20.425 & $\begin{array}{l}28 . \\
173\end{array}$ & 30.869 & 27.797 & 28.470 & 28.396 & 28.558 & 27.776 & 28.261 & 28.121 & 29.149 & 28.399 & 28.644 \\
\hline 6 & 30.189 & 31.029 & 32.666 & 31.281 & 29.243 & 29.312 & 29.078 & 30.939 & 31.139 & 28.610 & 29.761 & 30.881 & 28.998 \\
\hline 7 & 54.286 & 47.628 & 48.282 & 48.304 & 48.769 & 49.883 & 48.516 & 47.297 & 47.704 & 48.390 & 47.950 & 46.282 & 48.396 \\
\hline 8 & 56.546 & 52.292 & 52.306 & 53.306 & 51.389 & 53.031 & 51.074 & 52.286 & 52.420 & 52.291 & 51.215 & 52.699 & 50.896 \\
\hline
\end{tabular}

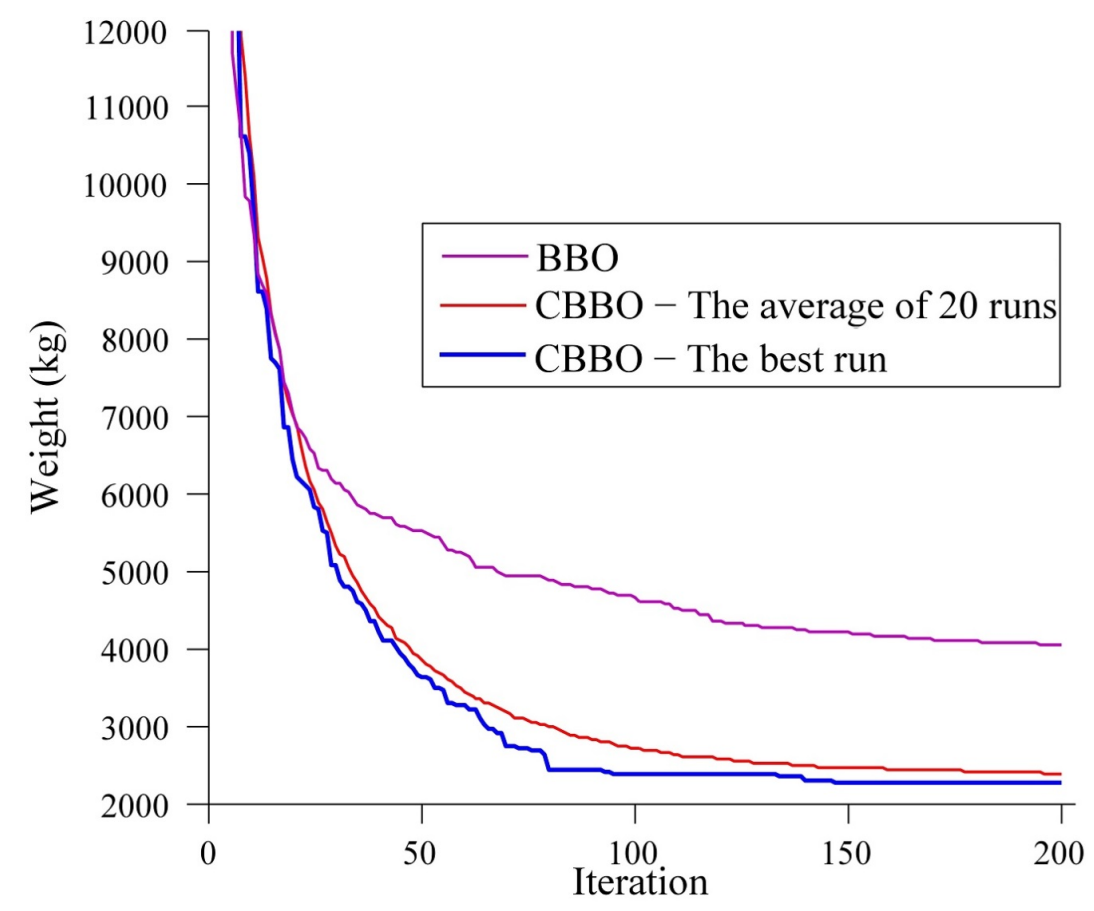

Fig. 7. Comparative convergence behaviors of the standard $\mathrm{BBO}$ and $\mathrm{CBBO}$ algorithms for 10-bar planar truss.

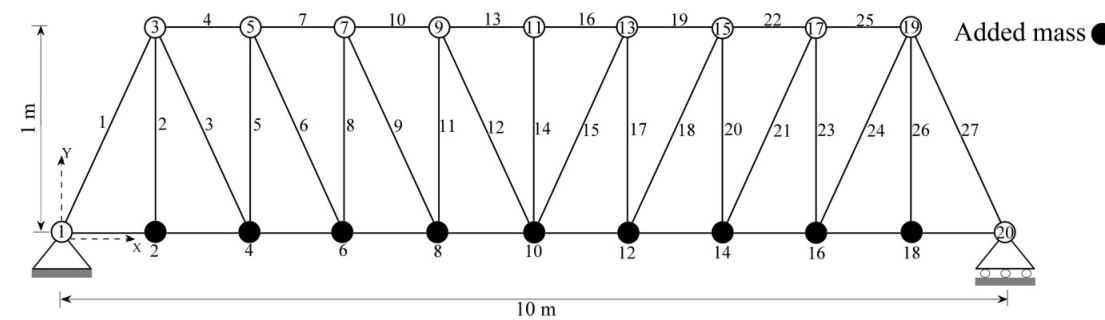

Fig. 8. Schematic of the simply-supported planar 37-bar truss. 
Tab. 4. Results of sensitivity analysis for best combination of the parameters of CBBO for the 37-bar planar truss problem.

\begin{tabular}{ccccccccc}
\hline & \multicolumn{9}{c}{ Parameters } & \multicolumn{5}{c}{ Weight $(\mathrm{kg})$} \\
Case & $N_{H}$ & $c_{1}$ & $c_{2}$ & $\alpha$ & Best & Mean & Std & Worst \\
1 & 20 & 1 & 1 & 0.05 & 360.85 & 362.02 & 1.00 & 364.49 \\
2 & 20 & 2 & 1 & 0.05 & 361.86 & 364.21 & 2.13 & 368.79 \\
3 & 20 & 1 & 2 & 0.05 & 361.91 & 363.79 & 2.24 & 369.49 \\
4 & 30 & 1 & 1 & 0.05 & 360.29 & 361.11 & 0.48 & 362.21 \\
5 & 30 & 2 & 1 & 0.05 & 361.63 & 362.73 & 0.95 & 364.57 \\
6 & 30 & 1 & 2 & 0.05 & 361.44 & 363.56 & 2.44 & 367.47 \\
7 & 40 & 1 & 1 & 0.05 & 360.44 & 361.15 & 0.33 & 361.64 \\
8 & 40 & 2 & 1 & 0.05 & 361.05 & 362.74 & 1.06 & 364.32 \\
9 & 40 & 1 & 2 & 0.05 & 361.83 & 362.77 & 1.32 & 366.32 \\
10 & 20 & 1 & 1 & 0.5 & 361.70 & 363.60 & 1.46 & 367.03 \\
11 & 20 & 2 & 1 & 0.5 & 364.58 & 367.51 & 1.68 & 370.28 \\
12 & 20 & 1 & 2 & 0.5 & 363.70 & 366.65 & 2.20 & 369.97 \\
13 & 30 & 1 & 1 & 0.5 & 361.24 & 363.10 & 1.10 & 364.90 \\
14 & 30 & 2 & 1 & 0.5 & 363.01 & 365.23 & 1.63 & 368.18 \\
15 & 30 & 1 & 2 & 0.5 & 363.94 & 366.21 & 2.60 & 372.83 \\
16 & 40 & 1 & 1 & 0.5 & 362.30 & 363.16 & 0.42 & 363.70 \\
17 & 40 & 2 & 1 & 0.5 & 361.70 & 364.16 & 1.67 & 367.04 \\
18 & 40 & 1 & 2 & 0.5 & 362.95 & 365.98 & 1.95 & 369.28 \\
\hline
\end{tabular}

Tab. 5. Optimized designs for the 37-bar planar truss problem; optimal nodal coordinates $\left(Y_{i}(\mathrm{~m})\right)$ and cross- sectional areas $A_{i}\left(\mathrm{~cm}^{2}\right)$.

\begin{tabular}{|c|c|c|c|c|c|c|c|c|}
\hline \multirow{2}{*}{$\begin{array}{c}\text { Design } \\
\text { variable }\end{array}$} & \multirow{2}{*}{$\begin{array}{c}\text { Wang et } \\
\text { al. 5. }\end{array}$} & \multirow{2}{*}{$\begin{array}{l}\text { Lingyun } \\
\text { et al. } 10 \text {. } \\
\text { NHGA }\end{array}$} & \multirow{2}{*}{$\begin{array}{c}\text { Gomes } \\
\text { PSO }\end{array}$} & \multicolumn{2}{|c|}{ Kaveh and Zolghadr } & \multirow{2}{*}{$\frac{12}{12}$} & \multicolumn{2}{|c|}{ Present work } \\
\hline & & & & css & $\begin{array}{c}\text { Enhanced } \\
\text { CSS }\end{array}$ & & BBO & CBBO \\
\hline$Y_{3}, Y_{19}$ & 1.2086 & 1.1998 & 0.9637 & 0.8726 & 1.0289 & 0.9482 & 0.94404 & 0.9794 \\
\hline$Y_{5}, Y_{17}$ & 1.5788 & 1.6553 & 1.3978 & 1.2129 & 1.3868 & 1.3439 & 1.25010 & 1.3411 \\
\hline$Y_{7}, Y_{15}$ & 1.6719 & 1.9652 & 1.5929 & 1.3826 & 1.5893 & 1.5043 & 1.39930 & 1.5403 \\
\hline$Y_{9}, Y_{13}$ & 1.7703 & 2.0737 & 1.8812 & 1.4706 & 1.6405 & 1.6350 & 1.54140 & 1.6861 \\
\hline$Y_{11}$ & 1.8502 & 2.3050 & 2.0856 & 1.5683 & 1.6835 & 1.7182 & 1.56390 & 1.7661 \\
\hline$A_{1}, A_{27}$ & 3.2508 & 2.8932 & 2.6797 & 2.9082 & 3.4484 & 2.6208 & 3.82130 & 2.6334 \\
\hline$A_{2}, A_{26}$ & 1.2364 & 1.1201 & 1.1568 & 1.0212 & 1.5045 & 1.0397 & 1.01400 & 1.0787 \\
\hline$A_{3}, A_{24}$ & 1.0000 & 1.0000 & 2.3476 & 1.0363 & 1.0039 & 1.0464 & 1.83660 & 1.0000 \\
\hline$A_{4}, A_{25}$ & 2.5386 & 1.8655 & 1.7182 & 3.9147 & 2.5533 & 2.7163 & 2.92040 & 2.5520 \\
\hline$A_{5}, A_{23}$ & 1.3714 & 1.5962 & 1.2751 & 1.0025 & 1.0868 & 1.0252 & 1.09570 & 1.1357 \\
\hline$A_{6}, A_{21}$ & 1.3681 & 1.2642 & 1.4819 & 1.2167 & 1.3382 & 1.5081 & 1.13920 & 1.2483 \\
\hline$A_{7}, A_{22}$ & 2.4290 & 1.8254 & 4.685 & 2.7146 & 3.1626 & 2.3750 & 3.25890 & 3.1168 \\
\hline$A_{8}, A_{20}$ & 1.6522 & 2.0009 & 1.1246 & 1.2663 & 2.2664 & 1.4498 & 1.42990 & 1.4849 \\
\hline$A_{9}, A_{18}$ & 1.8257 & 1.9526 & 2.1214 & 1.2668 & 1.4499 & 1.51360 & 1.4634 & \\
\hline$A_{10}, A_{19}$ & 2.3022 & 1.9705 & 3.86 & 4.0274 & 1.7518 & 2.5327 & 4.01820 & 2.4885 \\
\hline$A_{11}, A_{17}$ & 1.3103 & 1.8294 & 2.9817 & 1.3364 & 2.7789 & 1.2358 & 2.67270 & 1.2502 \\
\hline$A_{12}, A_{15}$ & 1.4067 & 1.2358 & 1.2021 & 1.0548 & 1.4209 & 1.3528 & 1.18160 & 1.3661 \\
\hline$A_{13}, A_{16}$ & 2.1896 & 1.4049 & 1.2563 & 2.8116 & 1.0100 & 2.9144 & 2.40820 & 2.1451 \\
\hline$A_{14}$ & 1.0000 & 1.0000 & 3.3276 & 1.1702 & 2.2919 & 1.0085 & 1.22720 & 1.0000 \\
\hline $\begin{array}{l}\text { Weight } \\
(\mathrm{kg})\end{array}$ & 366.5 & 368.84 & 377.20 & 362.84 & 362.38 & 360.40 & 369.10 & 360.29 \\
\hline $\begin{array}{l}\text { Mean } \\
\text { weight } \\
(\mathrm{kg})\end{array}$ & $\mathrm{N} / \mathrm{A}$ & 378.8259 & 381.2 & 366.77 & 365.75 & 362.21 & 377.40 & 361.33 \\
\hline $\begin{array}{c}\text { Standard } \\
\text { deviation } \\
(\mathrm{kg})\end{array}$ & $\mathrm{N} / \mathrm{A}$ & 9.0325 & 4.26 & 3.742 & 3.461 & 1.68 & 7.35 & 0.67 \\
\hline
\end{tabular}


Tab. 6. Natural frequencies $(\mathrm{Hz})$ evaluated at the optimized designs for the simply supported 37-bar planar truss.

\begin{tabular}{lcccccccr}
\hline $\begin{array}{c}\text { Frequency } \\
\text { No. }\end{array}$ & $\begin{array}{c}\text { Wang et } \\
\text { al. [5] }\end{array}$ & $\begin{array}{c}\text { Lingyun } \\
\text { et al. [10] }\end{array}$ & $\begin{array}{c}\text { Gomes } \\
\text { [11] }\end{array}$ & \multicolumn{2}{c}{ Kaveh and Zolghadr 12} & $29]$ & \multicolumn{2}{c}{ Present work } \\
\hline & & NHGA & PSO & CSS & $\begin{array}{c}\text { Enhanced } \\
\text { CSS }\end{array}$ & DPSO & BBO & CBBO \\
\hline 1 & 20.0850 & 20.0013 & 20.0001 & 20.0000 & 20.0028 & 20.0194 & 20.3110 & 20.029 \\
2 & 42.0743 & 40.0305 & 40.0003 & 40.0693 & 40.0155 & 40.0113 & 42.8990 & 40.013 \\
3 & 62.9383 & 60.0000 & 60.0001 & 60.6982 & 61.2798 & 60.0082 & 62.1780 & 60.028 \\
4 & 74.4539 & 73.0444 & 73.0440 & 75.7339 & 78.1100 & 76.9896 & 79.0920 & 76.811 \\
5 & 90.0576 & 89.8244 & 89.8240 & 97.6137 & 98.4100 & 97.2222 & 103.0100 & 96.862 \\
\hline
\end{tabular}

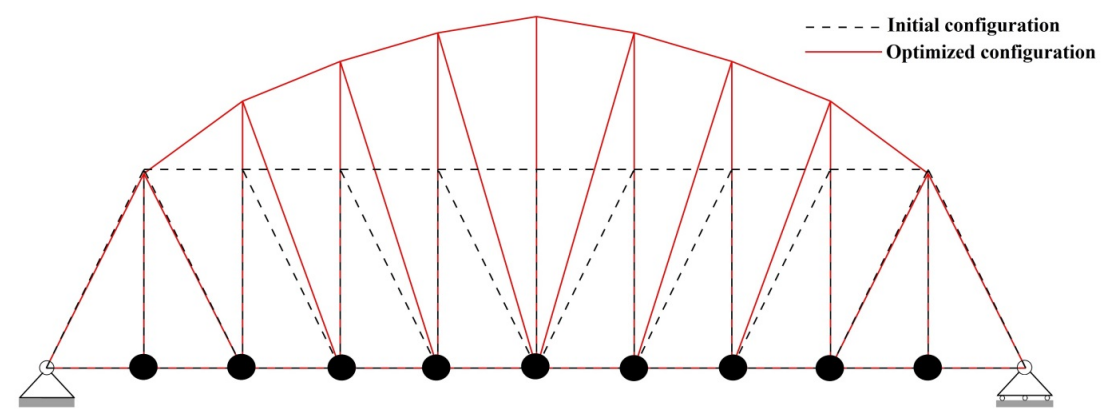

Fig. 9. Comparison of the optimized shape with the initial configuration of the simply-supported planar 37-bar truss.

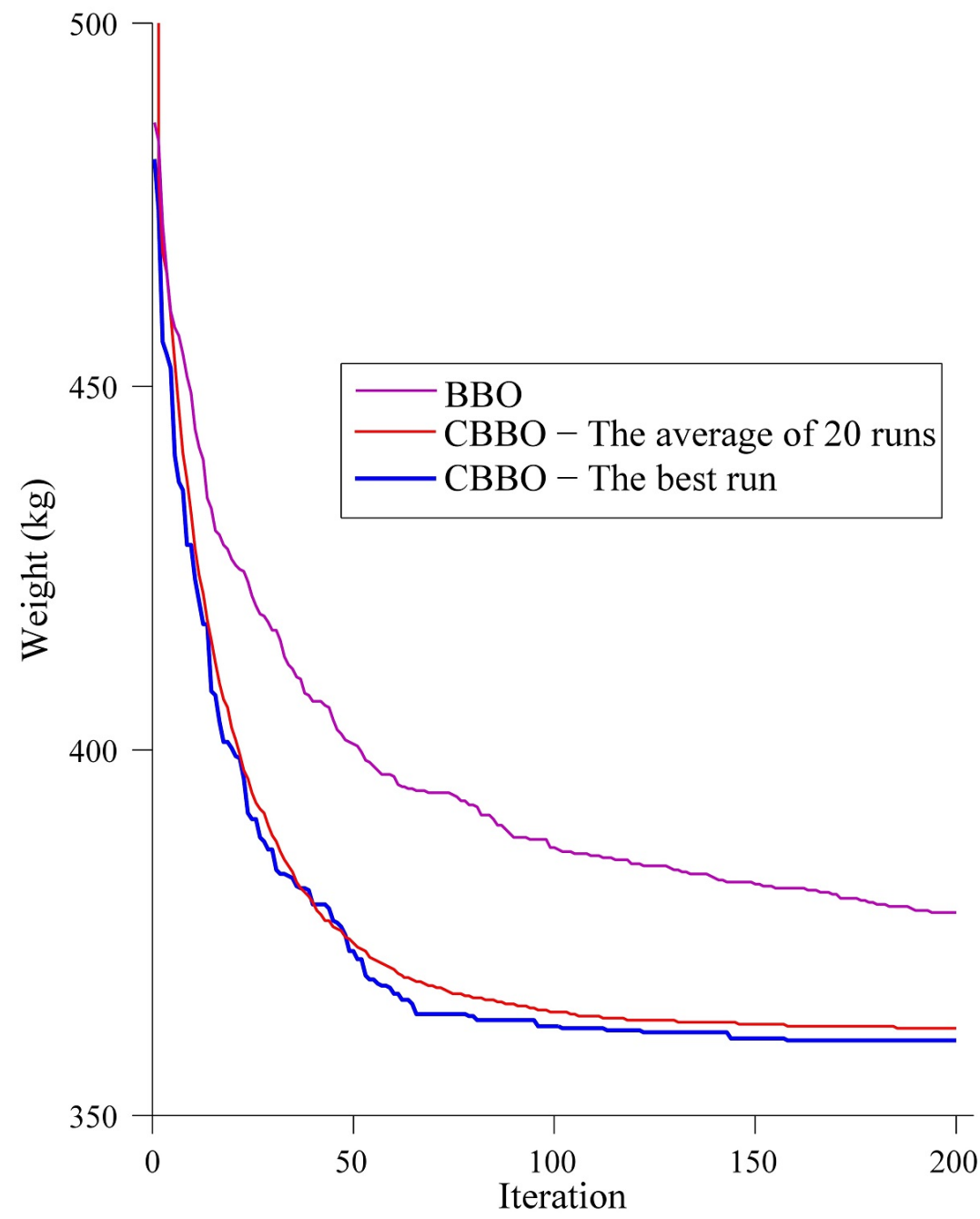

Fig. 10. Comparison of convergence diagrams of standard $\mathrm{BBO}$ and $\mathrm{CBBO}$ algorithms for the simply-supported planar 37-bar truss. 


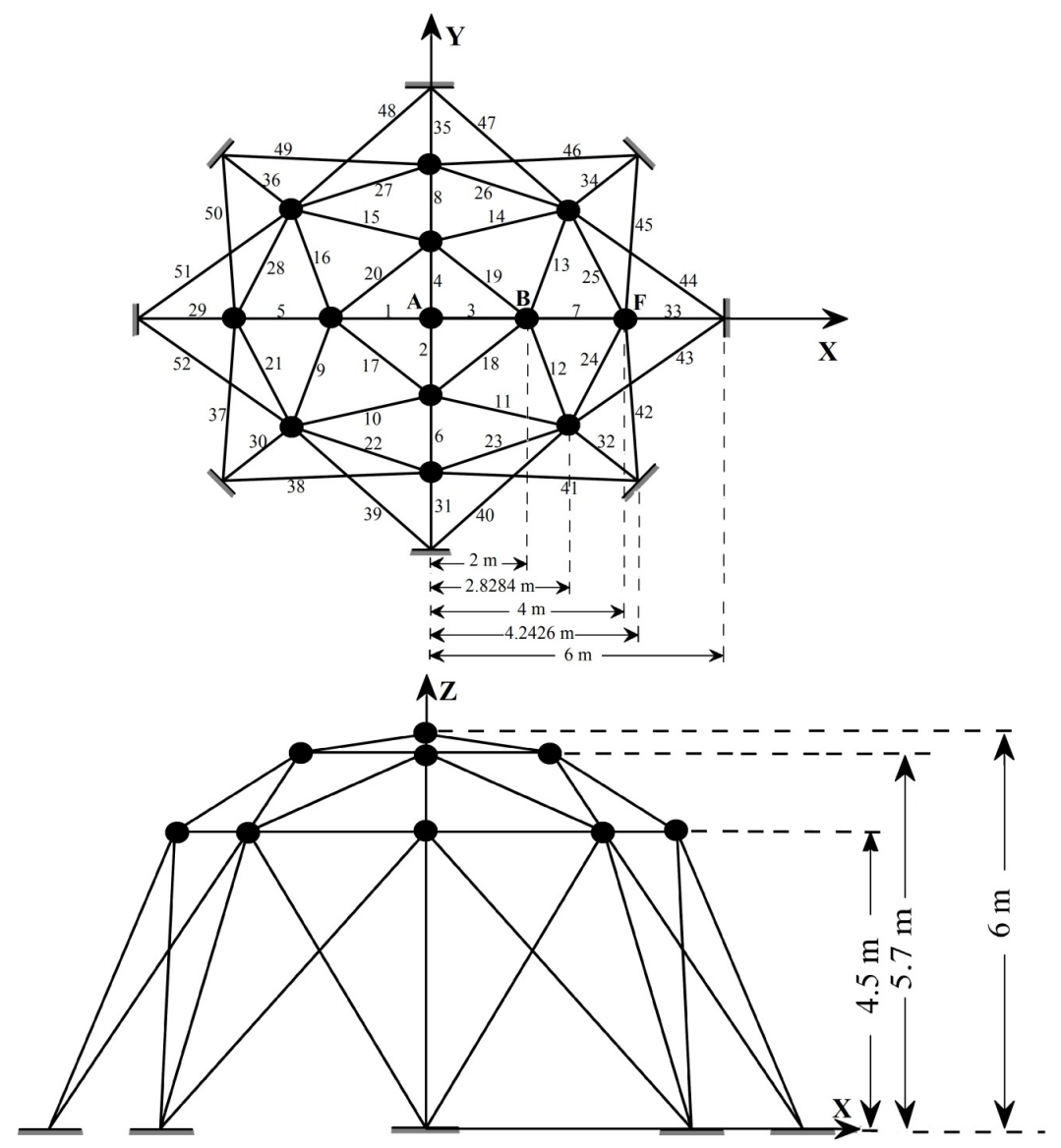

Fig. 11. Schematic of the initial layout of the spatial 52-bar space truss: (a) Top view (b) Side view.

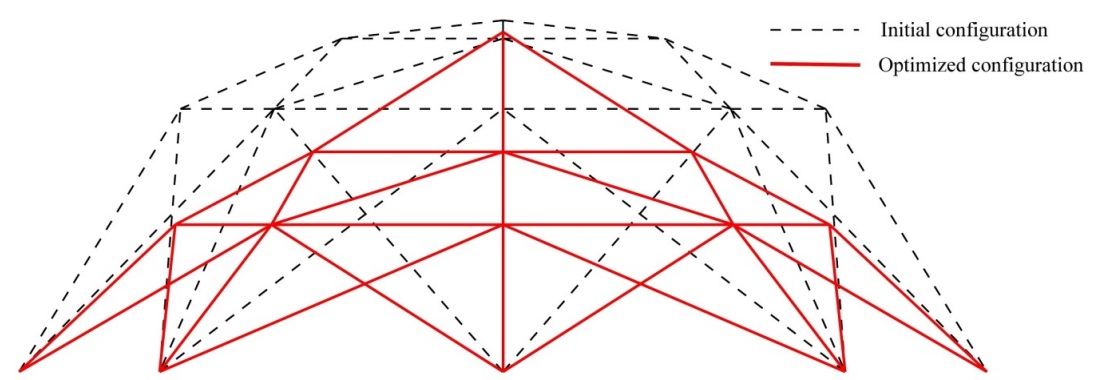

Fig. 12. Comparison of the optimized shape with the initial configuration of the 52-bar space truss.

Tab. 7. Element grouping adopted in the 52-bar space truss problem.

\begin{tabular}{cc}
\hline Group number & Elements \\
\hline 1 & $1,2,3,4$ \\
2 & $5,6,7,8$ \\
3 & $9,10,11,12,13,14,15,16$ \\
4 & $17,18,19,20$ \\
5 & $21,22,23,24,25,26,27,28$ \\
6 & $29,30,31,32,33,34,35,36$ \\
7 & $37,38,39,40,41,42,43,44$ \\
8 & $45,46,47,48,49,50,51,52$ \\
\hline
\end{tabular}




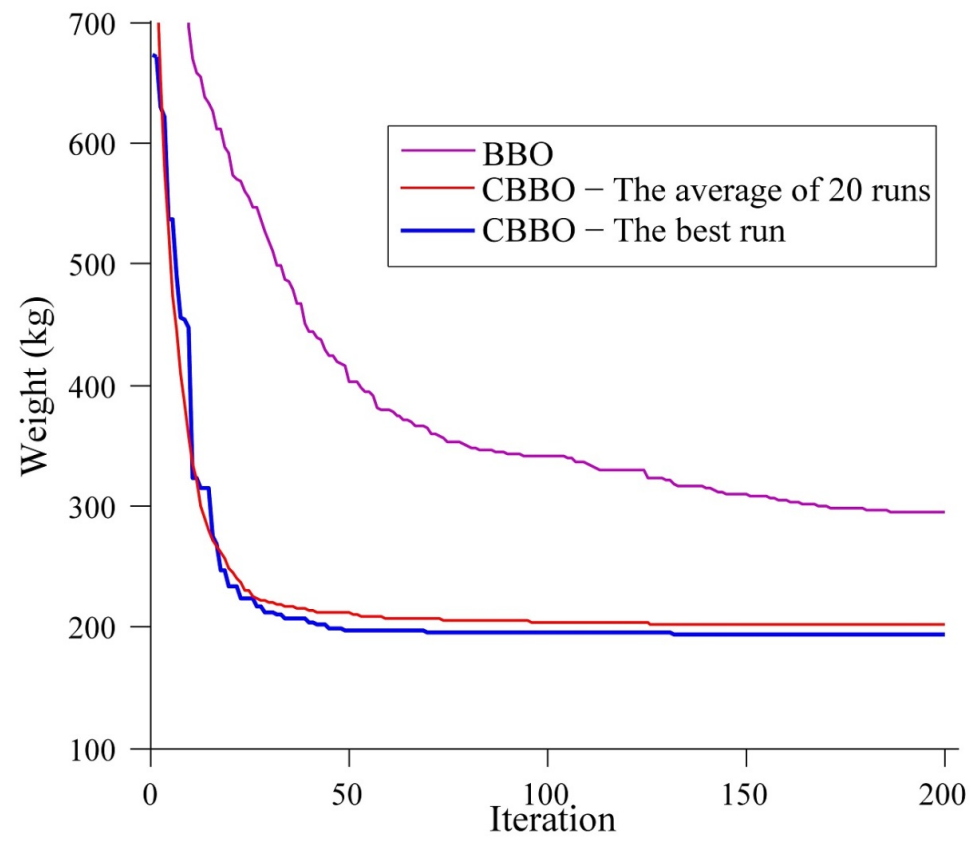

Fig. 13. Comparison of convergence curves of standard $\mathrm{BBO}$ and $\mathrm{CBBO}$ algorithms for the 52-bar space truss.

Tab. 8. Results of sensitivity analysis carried out to find the best combination of the parameters of CBBO for the 52-bar space truss problem.

\begin{tabular}{|c|c|c|c|c|c|c|c|c|}
\hline \multirow[b]{2}{*}{ Case } & \multirow[b]{2}{*}{$N_{H}$} & \multicolumn{2}{|c|}{ Parameters } & \multicolumn{5}{|c|}{ Weight (kg) } \\
\hline & & $c_{1}$ & $c_{2}$ & $\alpha$ & Best & Mean & Std & Worst \\
\hline 1 & 20 & 1 & 1 & 0.05 & 198.94 & 220.12 & 15.67 & 239.46 \\
\hline 2 & 20 & 2 & 1 & 0.05 & 195.65 & 229.46 & 50.14 & 330.67 \\
\hline 3 & 20 & 1 & 2 & 0.05 & 199.37 & 230.76 & 37.65 & 313.78 \\
\hline 4 & 30 & 1 & 1 & 0.05 & 204.63 & 227.75 & 34.15 & 316.42 \\
\hline 5 & 30 & 2 & 1 & 0.05 & 194.90 & 208.03 & 10.20 & 226.01 \\
\hline 6 & 30 & 1 & 2 & 0.05 & 196.49 & 206.97 & 13.50 & 242.73 \\
\hline 7 & 40 & 1 & 1 & 0.05 & 204.11 & 219.72 & 17.06 & 254.88 \\
\hline 8 & 40 & 2 & 1 & 0.05 & 194.09 & 199.83 & 4.06 & 206.53 \\
\hline 9 & 40 & 1 & 2 & 0.05 & 194.73 & 201.93 & 12.11 & 235.25 \\
\hline 10 & 20 & 1 & 1 & 0.5 & 206.21 & 244.34 & 55.23 & 393.03 \\
\hline 11 & 20 & 2 & 1 & 0.5 & 200.85 & 225.81 & 28.16 & 289.23 \\
\hline 12 & 20 & 1 & 2 & 0.5 & 205.36 & 240.00 & 42.64 & 329.92 \\
\hline 13 & 30 & 1 & 1 & 0.5 & 205.13 & 228.69 & 28.67 & 305.79 \\
\hline 14 & 30 & 2 & 1 & 0.5 & 199.90 & 216.39 & 26.79 & 291.87 \\
\hline 15 & 30 & 1 & 2 & 0.5 & 198.79 & 213.17 & 19.13 & 265.7 \\
\hline 16 & 40 & 1 & 1 & 0.5 & 199.70 & 210.01 & 11.35 & 238.10 \\
\hline 17 & 40 & 2 & 1 & 0.5 & 201.89 & 210.85 & 8.65 & 232.41 \\
\hline 18 & 40 & 1 & 2 & 0.5 & 199.38 & 211.31 & 9.73 & 232.11 \\
\hline
\end{tabular}


Tab. 9. Optimized designs obtained for the 52-bar space truss problem; optimal nodal coordinates and cross-sectional areas.

\begin{tabular}{|c|c|c|c|c|c|c|c|c|c|c|c|}
\hline \multirow[t]{2}{*}{ Design variable } & \multirow{2}{*}{$\begin{array}{l}\text { Lin et } \\
\text { al. } 30\end{array}$} & \multirow{2}{*}{$\begin{array}{l}\text { Lingyun } \\
\text { et al. } \\
10 \\
\text { NHGA }\end{array}$} & \multirow{2}{*}{$\begin{array}{c}\text { Gomes } \\
\qquad 11] \\
\text { PSO }\end{array}$} & \multicolumn{3}{|c|}{ Kaveh and Zolghadr } & \multirow{2}{*}{\multicolumn{2}{|c|}{213}} & \multirow{2}{*}{$\frac{29 .}{\text { DPSO }}$} & \multicolumn{2}{|c|}{ Present work } \\
\hline & & & & CSS & $\begin{array}{c}\text { Enhanced } \\
\text { CSS }\end{array}$ & & BSS- & & & $\mathrm{BBO}$ & CBBO \\
\hline$Z_{A}(\mathrm{~m})$ & 4.3201 & 5.8851 & 5.5344 & 5.2716 & 6.1590 & & 3310 & & 6.1123 & 5.4611 & 5.8162 \\
\hline$X_{B}(\mathrm{~m})$ & 1.3153 & 1.7623 & 2.0885 & 1.5909 & 2.2609 & & 1340 & & 2.2343 & 1.5177 & 2.3525 \\
\hline$Z_{B}(\mathrm{~m})$ & 4.1740 & 4.4091 & 3.9283 & 3.7093 & 3.9154 & & 7190 & & 3.8321 & 4.0582 & 3.7684 \\
\hline$X_{F}(\mathrm{~m})$ & 2.9169 & 3.4406 & 4.0255 & 3.5595 & 4.0836 & & 9350 & & 4.0316 & 3.5204 & 4.0484 \\
\hline$Z_{F}(\mathrm{~m})$ & 3.2676 & 3.1874 & 2.4575 & 2.5757 & 2.5106 & & 5000 & & 2.5036 & 2.7484 & 2.5000 \\
\hline$A_{1}\left(\mathrm{~cm}^{2}\right)$ & 1.0000 & 1.0004 & 0.3696 & 1.0464 & 1.0335 & & 0000 & & 1.0001 & 1.5196 & 1.0000 \\
\hline$A_{2}\left(\mathrm{~cm}^{2}\right)$ & 1.3300 & 2.1417 & 4.1912 & 1.7295 & 1.0960 & & 3056 & & 1.1397 & 1.1760 & 1.0000 \\
\hline$A_{3}\left(\mathrm{~cm}^{2}\right)$ & 1.5800 & 1.4858 & 1.5123 & 1.6507 & 1.2449 & & 4230 & & 1.2263 & 1.1046 & 1.1836 \\
\hline$A_{4}\left(\mathrm{~cm}^{2}\right)$ & 1.0000 & 1.4018 & 1.5620 & 1.5059 & 1.2358 & & 3851 & & 1.3335 & 1.5884 & 1.5035 \\
\hline$A_{5}\left(\mathrm{~cm}^{2}\right)$ & 1.7100 & 1.9116 & 1.9154 & 1.7210 & 1.4078 & & 4226 & & 1.4161 & 1.0948 & 1.3967 \\
\hline$A_{6}\left(\mathrm{~cm}^{2}\right)$ & 1.5400 & 1.0109 & 1.1315 & 1.0020 & 1.0022 & & 0000 & & 1.0001 & 1.1219 & 1.0000 \\
\hline$A_{7}\left(\mathrm{~cm}^{2}\right)$ & 2.6500 & 1.4693 & 1.8233 & 1.7415 & 1.6024 & & 5562 & & 1.5750 & 2.5201 & 1.5787 \\
\hline$A_{8}\left(\mathrm{~cm}^{2}\right)$ & 2.8700 & 2.1411 & 1.0904 & 1.2555 & 1.4596 & & 4485 & & 1.4357 & 1.8206 & 1.4103 \\
\hline Weight (kg) & 298.00 & 236.050 & 228.380 & 205.237 & 197.337 & & 7.309 & & 195.351 & 232.36 & 194.09 \\
\hline Mean weight (kg) & $\mathrm{N} / \mathrm{A}$ & 274.164 & 234.3 & 213.101 & 205.617 & & $\mathrm{~N} / \mathrm{A}$ & & 198.71 & 294.48 & 201.27 \\
\hline Standard deviation $(\mathrm{kg})$ & $\mathrm{N} / \mathrm{A}$ & 37.462 & 5.22 & 7.391 & 6.924 & & N/A & & 13.85 & 39.76 & 4.93 \\
\hline
\end{tabular}

Tab. 10. Natural frequencies (Hz) evaluated at the optimal designs for the 52-bar space truss.

\begin{tabular}{|c|c|c|c|c|c|c|c|c|c|}
\hline $\begin{array}{l}\text { Frequency } \\
\text { No. }\end{array}$ & $\begin{array}{c}\text { Lin et al. } \\
\quad 32\end{array}$ & $\begin{array}{l}\text { Lingyun et } \\
\text { al. [10 }\end{array}$ & Gomes 11 & & Kaveh and Zolghadr & $\begin{array}{lll}12 & 13 & 29\end{array}$ & & \multicolumn{2}{|c|}{ Present work } \\
\hline & & NHGA & PSO & CSS & $\begin{array}{c}\text { Enhanced } \\
\text { CSS }\end{array}$ & CSS-BBBC & DPSO & BBO & CBBO \\
\hline 1 & 15.2196 & 12.8051 & 12.751 & 9.246 & 11.849 & 12.987 & 11.3150 & 9.3486 & 12.796 \\
\hline 2 & 29.2837 & 28.6489 & 28.649 & 28.648 & 28.649 & 28.648 & 28.6480 & 28.6540 & 28.649 \\
\hline 3 & 29.2837 & 28.6489 & 28.649 & 28.699 & 28.659 & 28.679 & 28.6480 & 28.6610 & 28.649 \\
\hline 4 & 31.6847 & 29.5398 & 28.803 & 28.735 & 28.718 & 28.713 & 28.6500 & 28.6610 & 28.656 \\
\hline 5 & 33.1547 & 30.2443 & 29.230 & 29.223 & 29.192 & 30.262 & 28.6880 & 29.5260 & 29.663 \\
\hline
\end{tabular}

Tab. 11. Optimized designs $\left(\mathrm{cm}^{2}\right)$ obtained for the 120-bar dome truss problem.

\begin{tabular}{|c|c|c|c|c|c|c|}
\hline \multirow{2}{*}{$\begin{array}{c}\text { Element } \\
\text { group }\end{array}$} & \multicolumn{2}{|r|}{ Kaveh and Zolghad } & dr 13 15. & \multicolumn{3}{|c|}{ Present work } \\
\hline & CSS & CSS-BBBC & PSO & DPSO & BBO & CBBO \\
\hline 1 & 21.710 & 17.478 & 23.494 & 19.6070 & 19.9850 & 19.8120 \\
\hline 2 & 40.862 & 49.076 & 32.976 & 41.2900 & 34.8660 & 38.9570 \\
\hline 3 & 9.048 & 12.365 & 11.492 & 11.1360 & 16.8660 & 10.1770 \\
\hline 4 & 19.673 & 21.979 & 24.839 & 21.0250 & 21.9560 & 21.1170 \\
\hline 5 & 8.336 & 11.190 & 9.964 & 10.0600 & 15.1220 & 10.2610 \\
\hline 6 & 16.120 & 12.590 & 12.039 & 12.7580 & 9.8383 & 12.4840 \\
\hline 7 & 18.976 & 13.585 & 14.249 & 15.4140 & 16.5440 & 14.9530 \\
\hline Weight (kg) & 9204.51 & 9046.34 & 9171.93 & 8890.48 & 9427.18 & 8727.40 \\
\hline $\begin{array}{c}\text { Mean weight } \\
(\mathrm{kg})\end{array}$ & $N / A$ & $\mathrm{~N} / \mathrm{A}$ & 9251.84 & 8895.99 & 9763.32 & 8769.40 \\
\hline $\begin{array}{c}\text { Standard } \\
\text { deviation } \\
(\mathrm{kg})\end{array}$ & $N / A$ & $\mathrm{~N} / \mathrm{A}$ & 89.38 & 4.26 & 674.77 & 37.52 \\
\hline
\end{tabular}


Tab. 12. Natural frequencies $(\mathrm{Hz})$ evaluated at the optimized designs for the 120-bar dome truss.

\begin{tabular}{ccccccc}
\hline $\begin{array}{c}\text { Frequency } \\
\text { number }\end{array}$ & & \multicolumn{2}{c}{ Kaveh and Zolghadr 12} & & & \multicolumn{2}{c}{ Present work } \\
\hline & CSS & CSS-BBBC & PSO & DPSO & BBO & CBBO \\
\hline 1 & 9.002 & 9.000 & 9.0000 & 9.0001 & 9.0331 & 9.0006 \\
2 & 11.002 & 11.007 & 11.0000 & 11.0007 & 11.0732 & 11.0020 \\
3 & 11.006 & 11.018 & 11.0052 & 11.0053 & 11.0732 & 11.0020 \\
4 & 11.015 & 11.026 & 11.0134 & 11.0129 & 11.1359 & 11.0160 \\
5 & 11.045 & 11.048 & 11.0428 & 11.0471 & 11.2118 & 11.0860 \\
\hline
\end{tabular}
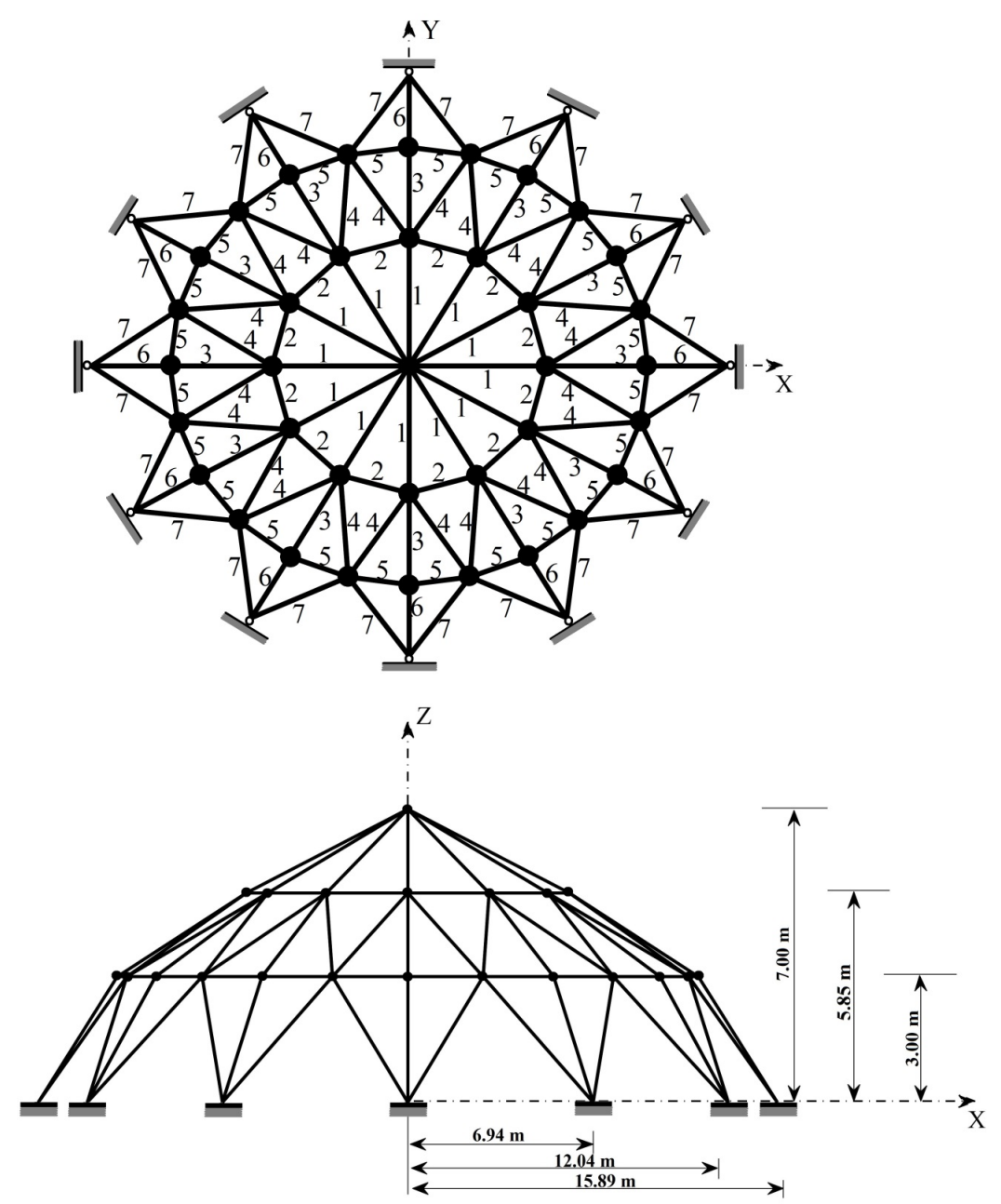

Fig. 14. Schematic of the 120-bar dome truss. 
Once again, the results of the sensitivity analysis carried out to find the best combination of parameters for $\mathrm{CBBO}$ are reported in Tab. 13. In this design example, it can be seen from Tab. 13 that the lowest structural weight is obtained for $N_{H}=40, c_{1}=$ $1 c_{2}=1$ and $\alpha=0.05$

The optimization results obtained by the standard BBO and CBBO are presented in Tab. 11 and are compared with those of the CSS [15], CSS-BBBC [15], PSO [13] and DPSO [13] approaches. It is quite evident that $\mathrm{CBBO}$ significantly outperforms other algorithms in terms of minimum weight, mean and standard deviation. On the other hand, the mean gained by the CBBO is also better than the best weights obtained by other methods as provided in Tab. 11 . It means that the CBBO algorithm obtained better design and lightest weight in all 20 independent runs. In addition, the natural frequencies obtained at the optimum designs are presented in Tab. 12 .

The convergence behaviors of the best solution and the average of 20 independent runs are presented in Fig. 15. As it can be seen from Fig. 15 that the best result is obtained after 120 iterations and it is clear that the performance of the proposed algorithm confirms the validity of the developed approach.

\section{Example 5. A 200-bar planar truss}

The last design example is the size optimization of a 200bar planar truss shown in Fig. 16. The Young's modulus is $2.1 \times 10^{11} \mathrm{~kg} / \mathrm{m}^{2}$ and the material density of truss members is $7860 \mathrm{~kg} / \mathrm{m}^{3}$ The minimum permitted cross-sectional area for the truss members is taken as $0.1 \mathrm{~cm}^{2}$ A non-structural mass of $100 \mathrm{~kg}$ are attached for all free nodes. Furthermore, the structure is subject to the first three frequency constraints as: $\omega_{1} \geq 5 \mathrm{~Hz}$, $\omega_{2} \geq 10 \mathrm{~Hz}, \omega_{3} \geq 15 \mathrm{~Hz}$. The members of the structure are divided into 29 groups as shown in Tab. 14. Hence, the optimization problem includes 19 design variables and it is relatively high dimensional optimization problem. Kaveh and Zolghadr [12] used this design example to size optimization with frequency constraints.

Another sensitivity analysis is carried out to find the best combination of internal parameters of the CBBO. In this design example, six cases of parameter settings are considered with the number of fifty habitats $\left(N_{H}=50\right)$, due to high dimensionality of the optimization problem. From Tab. 15 it can be observed that the lightest structural weight for this structure is obtained by $N_{H}=50, c_{1}=1, c_{2}=1$ and $\alpha=0.05$

Tab. 16 summarizes the optimal results obtained by both the standard BBO and CBBO algorithms. The results are compared with those CSS [12] and CSS-BBBC [12] approaches. Once again, it is evident that $\mathrm{CBBO}$ yields lighter structural weight than CSS [12] and CSS-BBBC [12]. The weight obtained by $\mathrm{CBBO}$ is $35.65 \mathrm{~kg}$ lighter than the weight found by CSS-BBBC [12], which is relatively considerable.

The natural frequencies evaluated at optimum designs are given in Tab. 17

In Fig. 17, the convergence behaviors of the average of 20 independent runs and the best run for $\mathrm{CBBO}$ are compared with original $\mathrm{BBO}$. Once again, it can be seen that $\mathrm{CBBO}$ can improve the performance of the original $\mathrm{BBO}$ and obtain the lightest weight. 
Tab. 13. Results of sensitivity analysis carried out to find the best combination of the parameters of CBBO for the 120-bar dome truss problem.

\begin{tabular}{|c|c|c|c|c|c|c|c|c|}
\hline \multirow[b]{2}{*}{ Case } & \multirow[b]{2}{*}{$N_{H}$} & \multicolumn{2}{|c|}{ Parameters } & \multicolumn{5}{|c|}{ Weight $(\mathrm{kg})$} \\
\hline & & $c_{1}$ & $c_{2}$ & $\alpha$ & Best & Mean & Std & Worst \\
\hline 1 & 20 & 1 & 1 & 0.05 & 8747.60 & 8810.30 & 45.04 & 8860.90 \\
\hline 2 & 20 & 2 & 1 & 0.05 & 8752.00 & 8835.50 & 89.03 & 9037.70 \\
\hline 3 & 20 & 1 & 2 & 0.05 & 8776.90 & 8896.60 & 116.69 & 9145.10 \\
\hline 4 & 30 & 1 & 1 & 0.05 & 8734.80 & 8767.50 & 25.08 & 8812.20 \\
\hline 5 & 30 & 2 & 1 & 0.05 & 8759.90 & 8838.70 & 61.43 & 8960.00 \\
\hline 6 & 30 & 1 & 2 & 0.05 & 8745.80 & 8873.10 & 86.30 & 8994.50 \\
\hline 7 & 40 & 1 & 1 & 0.05 & 8727.40 & 8767.70 & 41.00 & 8847.60 \\
\hline 8 & 40 & 2 & 1 & 0.05 & 8735.90 & 8853.50 & 109.81 & 9085.40 \\
\hline 9 & 40 & 1 & 2 & 0.05 & 8781.30 & 8866.3 & 71.26 & 8976.30 \\
\hline 10 & 20 & 1 & 1 & 0.5 & 8852.40 & 8988.20 & 143.15 & 9255.50 \\
\hline 11 & 20 & 2 & 1 & 0.5 & 8969.10 & 9224.60 & 192.49 & 9686.30 \\
\hline 12 & 20 & 1 & 2 & 0.5 & 8927.40 & 9256.90 & 333.18 & 9934.40 \\
\hline 13 & 30 & 1 & 1 & 0.5 & 8826.70 & 8918.70 & 67.95 & 9038.90 \\
\hline 14 & 30 & 2 & 1 & 0.5 & 8819.00 & 8955.80 & 119.15 & 9218.90 \\
\hline 15 & 30 & 1 & 2 & 0.5 & 8841.90 & 9136.00 & 280.52 & 9655.90 \\
\hline 16 & 40 & 1 & 1 & 0.5 & 8807.70 & 8861.20 & 54.23 & 9005.70 \\
\hline 17 & 40 & 2 & 1 & 0.5 & 8773.70 & 9030.00 & 134.72 & 9205.30 \\
\hline 18 & 40 & 1 & 2 & 0.5 & 8867.50 & 8976.10 & 175.45 & 9416.60 \\
\hline
\end{tabular}

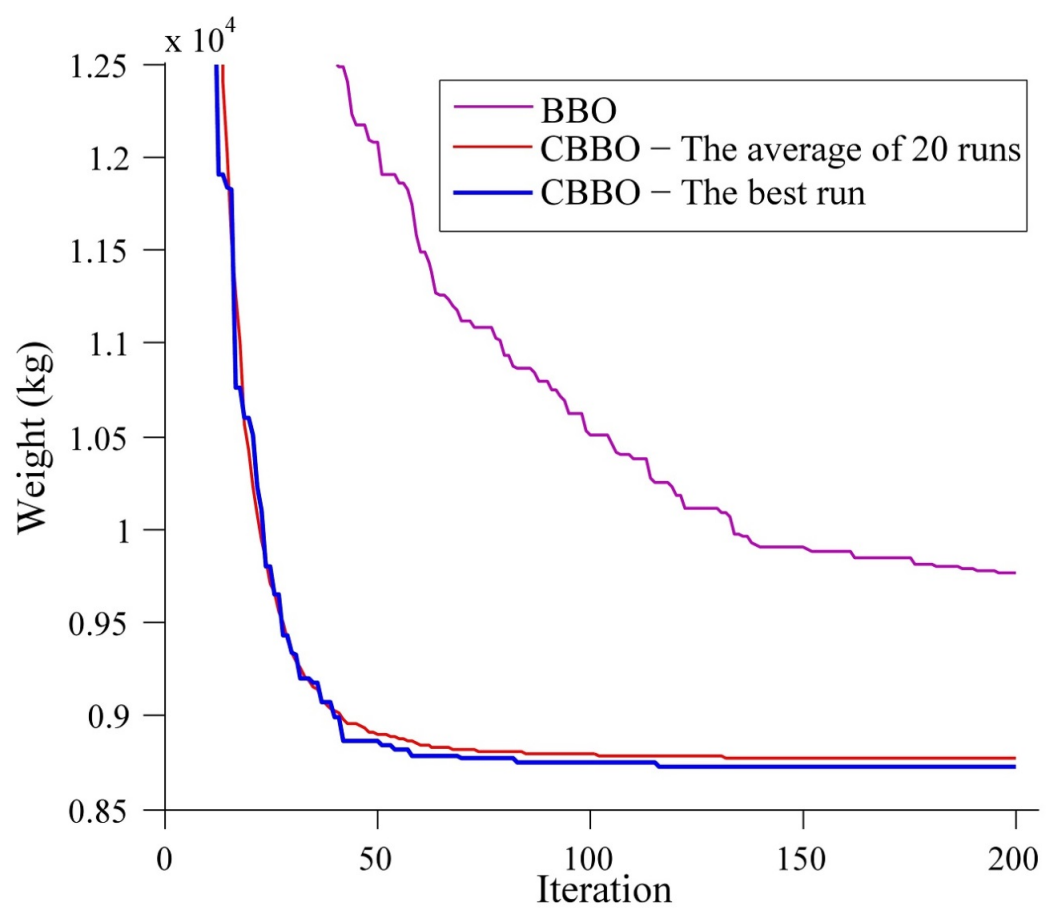

Fig. 15. Comparison of convergence diagrams of standard $\mathrm{BBO}$ and $\mathrm{CBBO}$ algorithms for the 120-bar dome truss. 


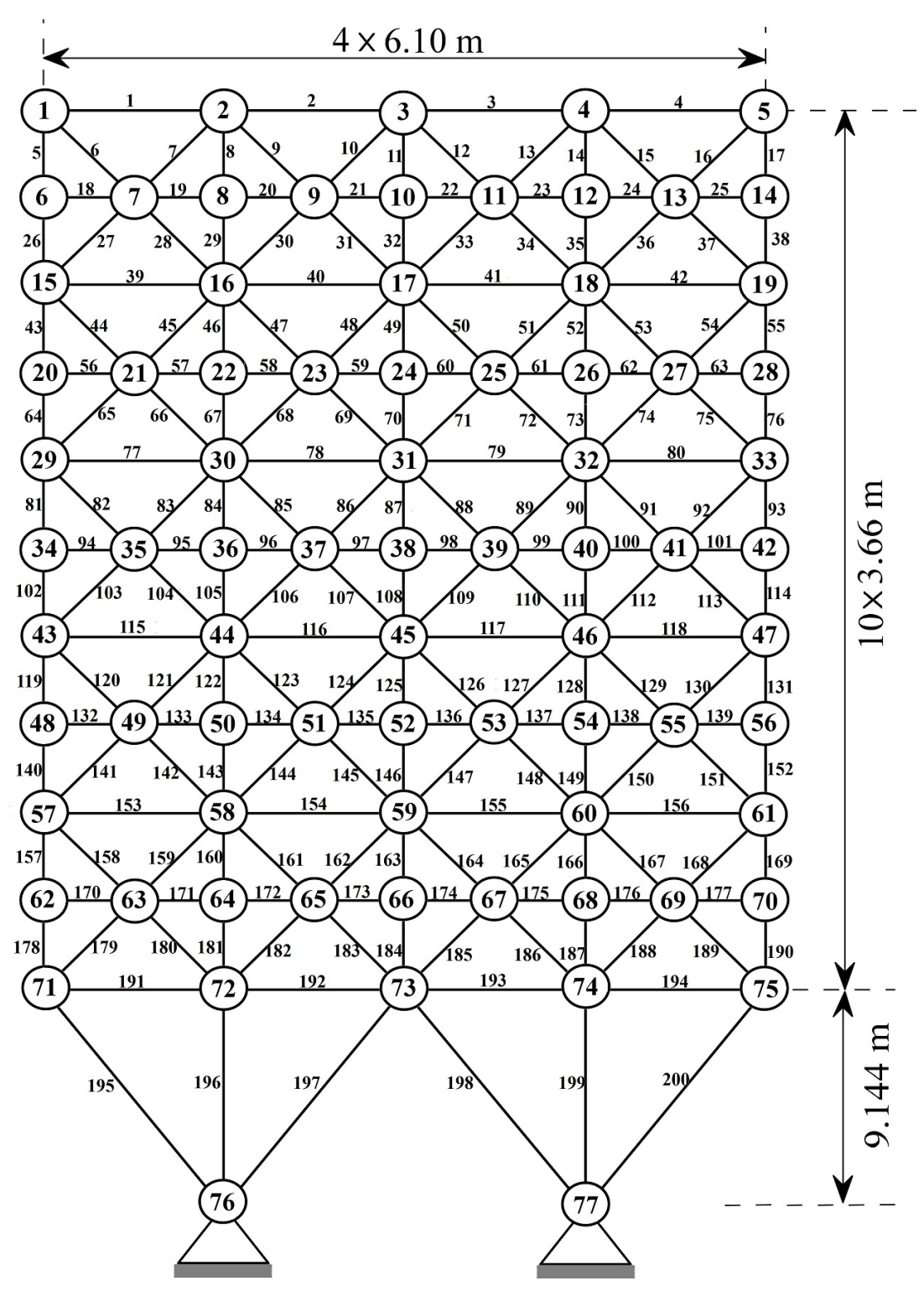

Fig. 16. Schematic of the 200-bar planar truss.

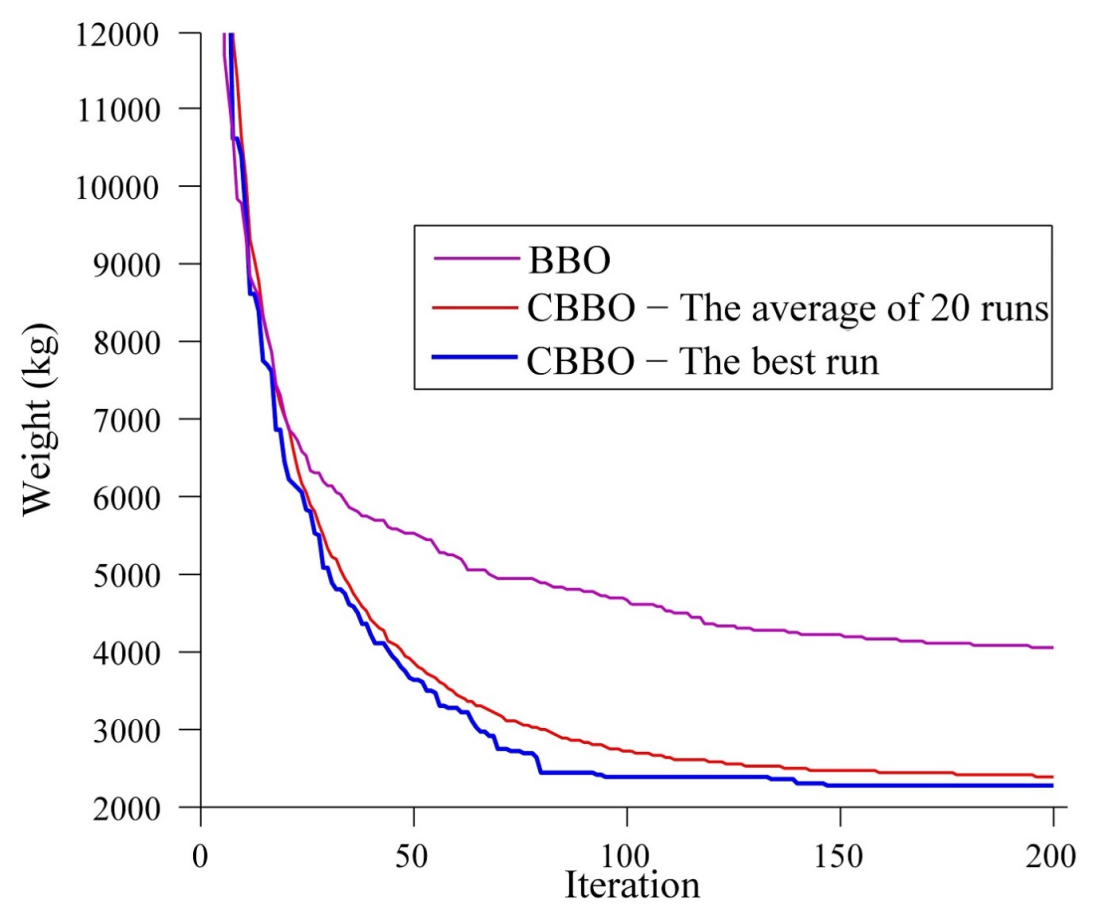

Fig. 17. Comparison of convergence curves of standard $\mathrm{BBO}$ and $\mathrm{CBBO}$ algorithms for the 200-bar planar truss. 
Tab. 14. Elements grouping adopted in the 200-bar planar truss.

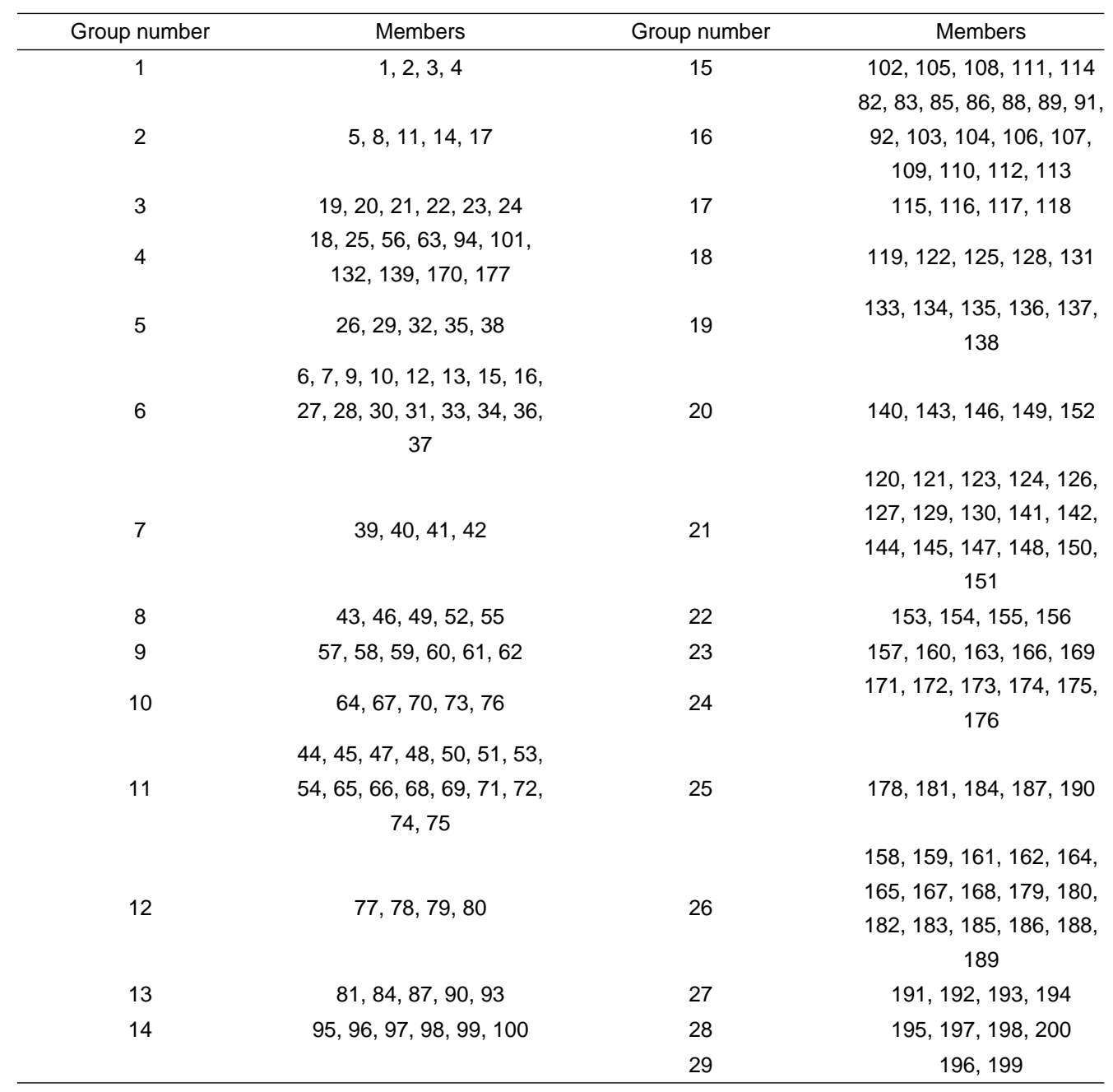


Tab. 15. Results of sensitivity analysis carried out to find the best combination of the parameters of CBBO for the 200-bar planar truss problem.

\begin{tabular}{ccccccccc}
\hline \multicolumn{7}{c}{ Parameters } & \multicolumn{7}{c}{ Weight $(\mathrm{kg})$} \\
\hline Case & $N_{H}$ & $c_{1}$ & $c_{2}$ & $\alpha$ & Best & Mean & Std & Worst \\
\hline 1 & 20 & 1 & 1 & 0.05 & 2583.60 & 3196.40 & 445.68 & 3839.50 \\
2 & 20 & 2 & 1 & 0.05 & 2693.80 & 2976.40 & 216.92 & 3395.90 \\
3 & 20 & 1 & 2 & 0.05 & 2764.70 & 2950.70 & 165.56 & 3251.80 \\
4 & 30 & 1 & 1 & 0.05 & 2449.50 & 2571.00 & 98.16 & 2773.70 \\
5 & 30 & 2 & 1 & 0.05 & 2421.60 & 2756.90 & 174.62 & 3019.10 \\
6 & 30 & 1 & 2 & 0.05 & 2492.10 & 2753.10 & 225.90 & 3146.00 \\
7 & 40 & 1 & 1 & 0.05 & 2365.20 & 2449.10 & 66.19 & 2574.40 \\
8 & 40 & 2 & 1 & 0.05 & 2518.00 & 2663.90 & 98.50 & 2835.80 \\
9 & 40 & 1 & 2 & 0.05 & 2405.30 & 2551.40 & 119.05 & 2744.60 \\
10 & 50 & 1 & 1 & 0.05 & 2262.96 & 2364.10 & 86.54 & 2569.40 \\
11 & 50 & 2 & 1 & 0.05 & 2421.60 & 2574.70 & 98.26 & 2709.80 \\
12 & 50 & 1 & 2 & 0.05 & 2355.00 & 2496.60 & 66.06 & 2562.10 \\
13 & 20 & 1 & 1 & 0.15 & 2717.60 & 3194.00 & 261.42 & 3682.80 \\
14 & 20 & 2 & 1 & 0.15 & 3139.60 & 3760.10 & 423.68 & 4600.30 \\
15 & 20 & 1 & 2 & 0.15 & 3052.90 & 3578.60 & 250.38 & 3887.90 \\
16 & 30 & 1 & 1 & 0.15 & 2628.30 & 2844.20 & 128.58 & 3043.80 \\
17 & 30 & 2 & 1 & 0.15 & 3277.10 & 3495.40 & 180.70 & 3817.20 \\
18 & 30 & 1 & 2 & 0.15 & 3017.90 & 3314.80 & 240.64 & 3676.20 \\
19 & 40 & 1 & 1 & 0.15 & 2502.50 & 2799.40 & 219.12 & 3166.70 \\
20 & 40 & 2 & 1 & 0.15 & 2902.10 & 3433.20 & 331.16 & 3910.30 \\
21 & 40 & 1 & 2 & 0.15 & 2900.10 & 3282.70 & 185.51 & 3552.80 \\
22 & 50 & 1 & 1 & 0.15 & 2599.90 & 2693.40 & 84.50 & 2891.50 \\
23 & 50 & 2 & 1 & 0.15 & 2893.10 & 3096.30 & 159.98 & 3321.70 \\
24 & 50 & 1 & 2 & 0.15 & 2706.80 & 3137.00 & 254.49 & 3582.40 \\
\hline & & & & & & & &
\end{tabular}


Tab. 16. Optimized designs $\left(\mathrm{cm}^{2}\right)$ obtained for the 200-bar planar truss problem.

\begin{tabular}{|c|c|c|c|c|}
\hline \multirow[t]{2}{*}{ Element group } & \multicolumn{2}{|c|}{ Kaveh and Zolghadr 12} & \multicolumn{2}{|c|}{ Present work } \\
\hline & CSS & CSS-BBBC & BBO & CBBO \\
\hline 1 & 1.2439 & 0.2934 & 2.1211 & 0.43194 \\
\hline 2 & 1.1438 & 0.5561 & 2.8942 & 0.42188 \\
\hline 3 & 0.3769 & 0.2952 & 2.7893 & 0.12477 \\
\hline 4 & 0.1494 & 0.1970 & 0.9380 & 0.19263 \\
\hline 5 & 0.4835 & 0.8340 & 2.0888 & 0.69798 \\
\hline 6 & 0.8103 & 0.6455 & 0.7550 & 0.99892 \\
\hline 7 & 0.4364 & 0.1770 & 0.1889 & 0.23163 \\
\hline 8 & 1.4554 & 1.4796 & 1.2664 & 1.29230 \\
\hline 9 & 1.0103 & 0.4497 & 0.1524 & 0.10000 \\
\hline 10 & 2.1382 & 1.4556 & 1.4054 & 2.06910 \\
\hline 11 & 0.8583 & 1.2238 & 3.0896 & 1.11570 \\
\hline 12 & 1.2718 & 0.2739 & 1.6398 & 0.21684 \\
\hline 13 & 3.0807 & 1.9174 & 6.1505 & 2.59770 \\
\hline 14 & 0.2677 & 0.1170 & 0.4268 & 0.10000 \\
\hline 15 & 4.2403 & 3.5535 & 3.9541 & 2.32330 \\
\hline 16 & 2.0098 & 1.3360 & 2.0265 & 1.58000 \\
\hline 17 & 1.5956 & 0.6289 & 2.5121 & 0.10000 \\
\hline 18 & 6.2338 & 4.8335 & 3.1521 & 6.78920 \\
\hline 19 & 2.5793 & 0.6062 & 2.4011 & 0.10000 \\
\hline 20 & 3.0520 & 5.4393 & 7.4375 & 6.67190 \\
\hline 21 & 1.8121 & 1.8435 & 1.7242 & 2.03730 \\
\hline 22 & 1.2986 & 1.8435 & 6.1541 & 0.29086 \\
\hline 23 & 5.8810 & 8.1759 & 5.0404 & 9.83100 \\
\hline 24 & 0.2324 & 0.3209 & 0.8897 & 0.60194 \\
\hline 25 & 7.7536 & 10.9800 & 7.7439 & 10.05500 \\
\hline 26 & 2.6871 & 2.9489 & 8.9341 & 4.13750 \\
\hline 27 & 12.5094 & 10.5243 & 9.4718 & 9.40200 \\
\hline 28 & 29.5704 & 20.4271 & 26.8170 & 17.71800 \\
\hline 29 & 8.2910 & 19.0983 & 20.6050 & 15.40400 \\
\hline Weight (kg) & 2559.86 & 2298.61 & 3403.22 & 2262.96 \\
\hline Mean weight (kg) & $\mathrm{N} / \mathrm{A}$ & $\mathrm{N} / \mathrm{A}$ & 4054.20 & 2370.90 \\
\hline $\begin{array}{l}\text { Standard deviation } \\
\qquad(\mathrm{kg})\end{array}$ & $\mathrm{N} / \mathrm{A}$ & $\mathrm{N} / \mathrm{A}$ & 435.08 & 78.94 \\
\hline
\end{tabular}

Tab. 17. Natural frequencies (Hz) evaluated at the optimized designs for the 200-bar planar truss.

\begin{tabular}{ccccc}
\hline Frequency No. & \multicolumn{2}{c}{ Kaveh and Zolghadr } & \multicolumn{2}{c}{ Present work } \\
\hline 1 & CSS & CSS-BBBC & BBO & CBBO \\
\hline 2 & 5.000 & 5.010 & 5.000 & 5.001 \\
3 & 15.961 & 12.911 & 16.212 & 13.569 \\
4 & 16.407 & 15.416 & 17.987 & 15.270 \\
5 & 20.748 & 17.033 & 24.947 & 17.190 \\
6 & 21.903 & 21.426 & 26.301 & 21.694 \\
\hline
\end{tabular}




\section{Concluding remarks}

This paper introduces a new optimization algorithm for size and shape optimization of truss structures with natural frequency constraints called the $\mathrm{CBBO}$, which combines the biogeography-based optimization and the Chaos theory. In this approach, the new chaotic migration and mutation operators are proposed to enhance the performance of standard BBO algorithm. Both such migration and the mutation operators can help to keep the diversity of whole population on a higher level to avoid habitat's trapping into local optima.

The performance of the proposed algorithm is evaluated using a set of five well-known truss design examples. In each design example, sensitivity analysis was performed for internal parameters $\left(N_{H}, c_{1}, c_{2}\right.$ and $\left.\alpha\right)$ of the CBBO algorithm to investigate how the CBBO is affected by these parameters and the best combination of them obtained. The results of the sensitivity analysis demonstrate that, for most design examples, the lowest structural weight is obtained for $c_{1}=1, c_{2}=1$ and $\alpha=0.05$.

The numerical results show the efficiency and capabilities of the $\mathrm{CBBO}$ in finding the lightest structural weight For all design examples, the structural weights obtained by CBBO are relatively lighter weights than those previously reported in the literature (except for Case 1 of first design example). Moreover, it is demonstrated that the standard deviation of optimized weights obtained by the proposed algorithm is less than other methods. It means that $\mathrm{CBBO}$ can provide higher quality and more robust designs.

\section{References}

1 Grandhi R, Structural optimization with frequency constraints - A review, AIAA Journal, 31(12), (1993), 2296-2303, DOI 10.2514/3.11928

2 Grandhi R, Venkayya V, Structural optimization with frequency constraints, AIAA Journal, 26(7), (1988), 858-866, DOI 10.2514/3.9979

3 Sedaghati R, Suleman A, Tabarrok B, Structural Optimization with Frequency Constraints Using the Finite Element Force Method, AIAA Journal, 40(2), (2002), 382--388, DOI 10.2514/2.1657

4 Sergeyev O, Mróz Z, Sensitivity analysis and optimal design of $3 D$ frame structures for stress and frequency constraints, Computers \& Structures, 75(2), (2000), 167-185, DOI 10.1016/S0045-7949(99)00088-7

5 Wang D, Zha W, Jiang J, Truss Optimization on Shape and Sizing with Frequency Constraints, AIAA Journal, 42(3), (2004), 622-630, DOI $10.2514 / 1.1711$

6 Goldberg D, Genetic algorithm in search, optimization and machine learning, Addison-Wesley, 1989.

7 Kennedy J, Eberhart R, Particle swarm optimization, IEEE international conference on neural networks, In:, 1995, pp. 1942-1948.

8 Kaveh A, Talatahari S, A novel heuristic optimization method: charged system search, Acta Mechanica, 213(3-4), 267-289, DOI 10.1007/s00707-0090270-4

9 Erol O, Eksin I, A new optimization method: Big Bang-Big Crunch, Advances in Engineering Software, 37(2), (2006), 106-111, DOI 10.1016/j.advengsoft.2005.04.005

10 Lingyun W, Mei Z, Guangming W, Guang M, Truss optimization on shape and sizing with frequency constraints based on genetic algorithm, Computational Mechanics, 35(5), (2005), 361-368, DOI 10.1007/s00466-004-0623-8

11 Gomes M, Truss optimization with dynamic constraints using a particle swarm algorithm, Expert Systems and Applications, 38(1), (2011), 957-968, DOI $10.1016 /$ j.eswa.2010.07.086

12 Kaveh A, Zolghadr A, Democratic PSO for truss layout and size optimization with frequency constraints, Computers \& Structures, 130, (2014), 10-21, DOI $10.1016 /$ j.compstruc.2013.09.002

13 Kaveh A, Zolghadr A, Truss optimization with natural frequency constraints using a hybridized CSS-BBBC algorithm with trap recognition capability, Computers \& Structures, 102-103, (2012), 14-27, DOI 10.1016/j.compstruc.2012.03.016

14 Simon D, Biogeography-Based Optimization, IEEE Transactions on Evolutionary Computation, 12(6), (2008), 702-713, DOI 10.1109/TEVC.2008.919004

15 MacArthur R, Wilson E, The Theory of Biogeography, Princeton University Press; USA, 1967.

16 Boussaid I, Chatterjee A, Siarry P, Ahmed-Nacer M, Biogeographybased optimization for constrained optimization problems, Computers \& Operations Research, 39(12), (2012), 3293-3304, DOI 10.1016/j.cor.2012.04.012

17 Simon D, Rarick R, Ergezer M, Du D, Analytical and numerical comparisons of biogeography-based optimization and genetic algorithms, Information Sciences, 181(7), (2011), 1224-1248, DOI 10.1016/j.ins.2010.12.006

18 Singh U, Kumar H, Kamal T, Design of Yagi-Uda Antenna Using Biogeography Based Optimization, IEEE Transactions on Antennas and Propagation, 58(10), (2010), 3375-3379, DOI 10.1109/TAP.2010.2055778

19 Bhattacharya A, Chattopadhyay P, Biogeography-Based Optimization for Different Economic Load Dispatch Problems, IEEE Transactions on Power Systems, 25(2), (2010), 1064-1077, DOI 10.1109/TPWRS.2009.2034525

20 Liu B, Wang L, Jin Y, Tang F, Huang D, Improved particle swarm optimization combined with chaos, Chaos, Solitons \& Fractals, 25(5), (2005), 1261-1271, DOI 10.1016/j.chaos.2004.11.095

21 Coelho L, Mariani V, Use of chaotic sequences in a biologically inspired algorithm for engineering design optimization, Expert Systems with Applications, 34(3), (2008), 1905-1913, DOI 10.1016/j.eswa.2007.02.002

22 Gao W, Liu S, Huang L, Particle swarm optimization with chaotic opposition-based population initialization and stochastic search technique, Communications in Nonlinear Science and Numerical Simulation, 17(11), (2012), 4316-4327, DOI 10.1016/j.cnsns.2012.03.015

23 Gandomi A, Yun G, Yang X, Talatahari S, Chaos-enhanced accelerated particle swarm optimization, Communications in Nonlinear Science and Numerical Simulation, 18(2), (2013), 327-340, DOI 10.1016/j.cnsns.2012.07.017

24 He Y, Zhou J, Lu N, Qin H, Lu Y, Differential evolution algorithm combined with chaotic pattern search, Kybernetika, 46(4), (2010), 684-696.

25 Alatas B, Chaotic harmony search algorithms, Applied Mathematics and Computation, 216(9), (2010), 2687-2699, DOI 10.1016/j.amc.2010.03.114

26 dos Santos Coelho L, Herrera B, Fuzzy Identification Based on a Chaotic Particle Swarm Optimization Approach Applied to a Nonlinear Yo-yo Motion System, IEEE Transactions on Industrial Electronics, 54(6), (2007), 32343245, DOI 10.1109/TIE.2007.896500

27 May R, Simple mathematical models with very complicated dynamics, Nature, 261(459-467), (1976).

28 Parlitz U, Ergezinger S, Robust communication based on chaotic spreading sequences, Physics Letters A, 188(2), (1994), 146-150, DOI 10.1016/03759601(84)90009-4

29 Kaveh A, Zolghadr A, Shape and size optimization of truss structures with frequency constraints using enhanced charged system search algorithm, Asian Journal of Civil Engineering, 12, (2011), 487-509.

30 Kaveh A, Mahdavi V, Optimal design of structures with multiple natural frequency constraints using a hybridized BB-BC/Quasi-Newton algorithm, Periodica Polytechnica Civil Engineering, 57(1), (2013), 27-38, DOI 10.3311/PPci.2139 
31 Kaveh A, Javadi S, An efficient hybrid particle swarm strategy, ray optimizer, and harmony search algorithm for optimal design of truss structures, Periodica Polytechnica Civil Engineering, 58(2), (2014), 155-171, DOI $10.3311 /$ PPci.7550

32 Kaveh A, Javadi S, Shape and size optimization of trusses with multiple frequency constraints using harmony search and ray optimizer for enhancing the particle swarm optimization algorithm, Acta Mechanica, 225(6), (2014), 1595-1605, DOI 10.1007/s00707-013-1006-z

33 Kaveh A, Zolghadr A, Comparison of nine meta-heuristic algorithms for optimal design of truss structures with frequency constraints, Advances in Engineering Software, 76, (2014), 9-30, DOI 10.1016/j.advengsoft.2014.05.012

34 Lin J, Chen W, Yu Y, Structural optimization on geometrical configuration and element sizing with statical and dynamical constraints, Computers \& Structures, 15(5), (1982), 507-515, DOI 10.1016/0045-7949(82)90002-5 